OPEN ACCESS

Edited by:

Ronny Scherer,

University of Oslo, Norway

Reviewed by:

Evgueni Borokhovski,

Concordia University, Canada

Gunter Kreutz,

University of Oldenburg, Germany

${ }^{*}$ Correspondence:

Tina M. Schwender

tina.schwender@tum.de

Specialty section: This article was submitted to Educational Psychology, a section of the journal

Frontiers in Psychology

Received: 11 December 2017 Accepted: 13 June 2018 Published: 17 July 2018

Citation: Schwender TM, Spengler S, Oedl C and Mess F (2018) Effects of Dance Interventions on Aspects of the Participants' Self: A Systematic Review. Front. Psychol. 9:1130. doi: 10.3389/fpsyg.2018.01130

\section{Effects of Dance Interventions on Aspects of the Participants' Self: A Systematic Review}

\author{
Tina M. Schwender*, Sarah Spengler, Christina Oedl and Filip Mess \\ Department of Sport and Health Sciences, Technical University of Munich, Munich, Germany
}

Background: Theoretical and empirical studies indicate that dance can strengthen the participants' self. The aim of the systematic review is to give an overview of studies investigating the effects of dance interventions on aspects of the self (e.g., self-concept/-esteem). Research questions are: (a) What is the evidence of the reported effects on different aspects of the self in children/adolescents and in adults? (b) Which study approaches and designs are used and what characterizes the interventions? (c) What are the qualitative facets of the implemented studies and what are issues for future research?

Methods: We searched online databases for English and German journal articles with the following main inclusion criteria: (i) Intervention study (qualitative and quantitative approaches) (ii) Investigation of aspects of the self (iii) Dance as intervention content. Two reviewers independently screened studies for eligibility using the PRISMA guidelines and assessed the methodological quality of the included studies.

Results: Out of 24 included studies, 11 investigate a sample of children/adolescents and 13 an adult sample. The review showed that dance interventions can have positive effects on aspects of the participants' self. The review of studies with qualitative methodologies suggests: children/adolescents benefit in body-related perceptions, self-trust, self-esteem, self-expression and perception of dance-abilities; adults benefit in self-expression, self-efficacy, self-/body-awareness, self-development and self-confidence. Studies with quantitative methodologies report improvement especially for body-related perceptions in both populations. Contradictory results exist concerning self-esteem/-efficacy. The evaluated studies show a heterogeneous nature of populations, intervention contents, timeframes, outcomes, research methods and study quality. Evidence for each of the aspects is still poor due to the small number of studies on each construct, inconsistent findings or methodological shortcomings.

Conclusions: This review indicates that dance may be a valuable approach to strengthen aspects of the self. However, as evidence for the different aspects of the self is still poor, further studies with high quality are required (e.g., large samples, active control group). Research considering the complexity and specificity of dance interventions in the design and reporting (e.g., choice of outcomes, presentation of intervention details) seem to be particularly suitable to capture the effects of dance considering its holistic nature.

Keywords: dance, self, intervention, systematic review, children, adolescents, adults 


\section{INTRODUCTION}

Representatives of the dance field emphasize the value of dance movement compared to movement in sports or in daily routine (Laban, 1948; Haselbach, 1976; Fritsch, 1988; Peter-Bolaender, 1991). Unlike normative sports, dance offers the opportunity to integrate the variety of movement possibilities. Moreover, dance movement differs from most movements in sports and daily routine regarding internal and external orientation: according to Ullmann, in dance the moving person immerses in the process of moving themself without paying attention to the practical result of the movement action (Ullmann, 2001). Gurley et al. also emphasize its difference with respect to goal-oriented or competitive aspects of sports movement and point out the expressive, creative and aesthetic character of dance movement (Gurley et al., 1984). Dance gives the opportunity to involve different senses and connects movement to music with selfexpression; therefore, it is seen as activity that addresses various facets of the personality (Kirsch, 2005; Kaufmann, 2011; StuderLüthi and Züger, 2012). In accord with this presumption, especially representatives of the dance education value dance as a specific opportunity to raise self- and body-awareness (Fritsch, 1988; Kirsch, 2005). Rudolf von Laban's work Modern Educational Dance pursues the development of the individual and substantially influences dance teachers' work to this day (Laban, 1948). The aim of dance education in Laban's tradition is neither artistic nor technical perfection but the beneficial effect of the creative activity upon the personality of the individual at any age. As these theoretical explanations indicate that dance has the potential to especially strengthen aspects of the self, this review intends to focus on this psychological construct.

The self, its' complexity and structure is the subject of different scientific disciplines like educational theory and psychology (Asendorpf and Neyer, 2012; Peichl, 2013). Baumeister defines the self as the totality of a person including the physical self and the self that is constructed out of meaning (Baumeister, 1991). Schuetz outlines two components of the self (Schütz, 2003): it encompasses self-concept as the cognitive-descriptive part and self-esteem as the emotional-affective component. Selfesteem results from the subjective evaluations of the self-related knowledge accumulated in self-concept. The superordinate term self-concept implies a person's self-perceptions and is essential to approach the question "Who am I?" (Amelang et al., 2011). Current research (Marsh and Hattie, 2011) still emphasizes the multidimensional, hierarchical model of self-concept proposed by Marsh and Shavelson (1985). Marsh and Hattie point out that this hypothetical construct could be valuable in explaining a person's behavior (Marsh and Hattie, 2011). Shaped by the experiences with the individual surroundings and by the interpretation and evaluation of the same, it functions as both outcome and mediator. According to Amelang, the expectations of self-efficacy are included in self-concept; the expectations of self-efficacy are defined as a person's beliefs in their competencies and their ability to practice them in adequate situations (Amelang et al., 2011). The fact that self-perceptions influence a person's behavior explains their relevance.
According to Block and Kissel, the interacting system of body and mind is reflected in the holistic activity of dancing: the authors see dance as "essence of embodiment," as dance expresses the meaning of an embodied being-inthe-world (Block and Kissell, 2001). The holistic idea of an interaction of body and mind corresponds to the embodiment theory. Following the embodiment theory there are interplays of mind, body and environment (Tschacher and Bergomi, 2011). Thereby human mind is seen as embedded in the body, which, in turn, is integrated into the environment. Koch stresses the bidirectionality assumption between the motor system and the cognitive-affective system (Koch, 2011). Consequently, motor behavior and body movements can be both the reason for and effect of psychological experience (Storch et al., 2011). Results in the experimental field of movement feedback support the direction of action in which movement or body posture impact a person's affect, attitude and perception (Koch, 2011; Storch et al., 2011). Hence, it seems reasonable that psychological constructs are influenced in the process of dancing.

Current literature offers reviews that point out the effects of dance interventions. For example, Burkhardt and Brennan conducted a review of controlled trials on the effects of recreational dance interventions on the health and wellbeing of children and young people (Burkhardt and Brennan, 2012). They report that recreational dance can improve cardiovascular fitness and bone health and can contribute to preventing or reducing obesity. They also refer to some studies that find positive effects on the participants' self-concept, body image and anxiety. However, especially for the psychosocial findings they state limited evidence. Moreover, a number of reviews exist in the field of "Dance Movement Therapy (DMT)" summarizing the effects of this movement-oriented form of psychotherapy on different outcomes (Strassel et al., 2011; Kiepe et al., 2012; Koch et al., 2014). For example, Strassel et al. undertook a systematic review of randomized controlled trials and reviews on the effects of DMT (Strassel et al., 2011). They state that benefits in terms of quality of life, self-esteem, or coping with a disease are the most reported positive effects. However, the identified reviews that examine the impact of dance interventions concentrate on certain populations, study approaches, settings, outcomes or physical benefits in particular (Keogh et al., 2009; Burkhardt and Brennan, 2012; Kiepe et al., 2012; Guzmán-García et al., 2013; Hwang and Braun, 2015; Rodrigues-Krause et al., 2016). Two reviews point out the benefits of art projects without considering the inherent value of dance on its own (Daykin et al., 2008; Bungay and Vella-Burrows, 2013).

Therefore, this systematic review aims at giving an overview of studies that investigate the effects of a dance intervention on aspects of the participants' self. We include studies with quantitative as well as qualitative methodologies following the call of making use of all forms of evidence (Dixon-Woods et al., 2005). In detail, this review focuses the following research questions: (a) What is the evidence of the reported effects on different aspects of the self in children/adolescents and in adults? (b) Which study approaches and designs are used and what characterizes the interventions (contents, timeframes)? (c) What 
are the qualitative facets of the implemented studies and what are issues for future research?

\section{METHODS}

The systematic review was conducted according to the PRISMA guidelines (Moher et al., 2015). PRISMA provides checklists and recommendations to authors of reviews and meta-analyses to ensure transparency, validity, and reproducibility.

\section{Search Strategy}

One author (TS) searched the electronic databases Web of Science, Medline, Psyndex, PsycINFO, PsycARTICLES, Teacher Reference Center, Education Source, ERIC, SPORTDiscus, SocINDEX, and Scopus for relevant studies. Language was restricted to English or German. There were no limitations concerning the publication period. The search included three main aspects: (i) Outcome/topic "aspects of the self"; (ii) Intervention; (iii) Content "dance." The following search term was used (e.g., Web of Science): ("Self competenc*” OR Self OR Perception* OR "Physic* Competenc*" OR Abilit* OR Image* OR Awareness* OR Identit* OR Personal*) AND (Intervention* OR Program* OR Training* OR Experiment* OR Treatment* OR Participation* OR Instruction* OR Exercise* OR Course*) AND (Danc* OR "Hip Hop" OR Ballet). The first data collection was completed in May 2016. An update search was undertaken in March 2017 (Date of last search: 15.03.17). We used the same search term but made an additional restriction to the publication date. The review protocol can be found on "PROSPERO" under the registration number CRD42016039288. The protocol presents additional information concerning the search levels and the search terms for all databases.

\section{Inclusion and Exclusion Criteria}

Table 1 contains a list of the terms determining our search and reasons for inclusion/exclusion. We used the following eligibility criteria: (i) The study had to be an intervention study. Any type of intervention study was included (qualitative and quantitative approaches, randomized control trials, quasiexperimental design trials, pilot studies). (ii) The study had to investigate at least one aspect of the self. The terms that arise from the definitions built the base for our search. (iii) The intervention content had to be dance. Studies with any kind of dance forms are included. (iv) The study had to be published as a journal article in English or German. We decided to include only journal articles to guarantee a certain quality standard of our included studies in terms of e.g., content-related, methodical, linguistic, and structural aspects.

Intervention studies were excluded if dance was only one part among other contents (e.g., general physical activities programs), because the inherent value of dance cannot be captured. Moreover, these programs differ in terms of their composition of different sport types/subfields and the number of subfields beside dance. Studies working with dance labeled

${ }^{1}$ International prospective register of systematic reviews. https://www.crd.york.ac. uk/PROSPERO/.
TABLE 1 | Inclusion and exclusion criteria.

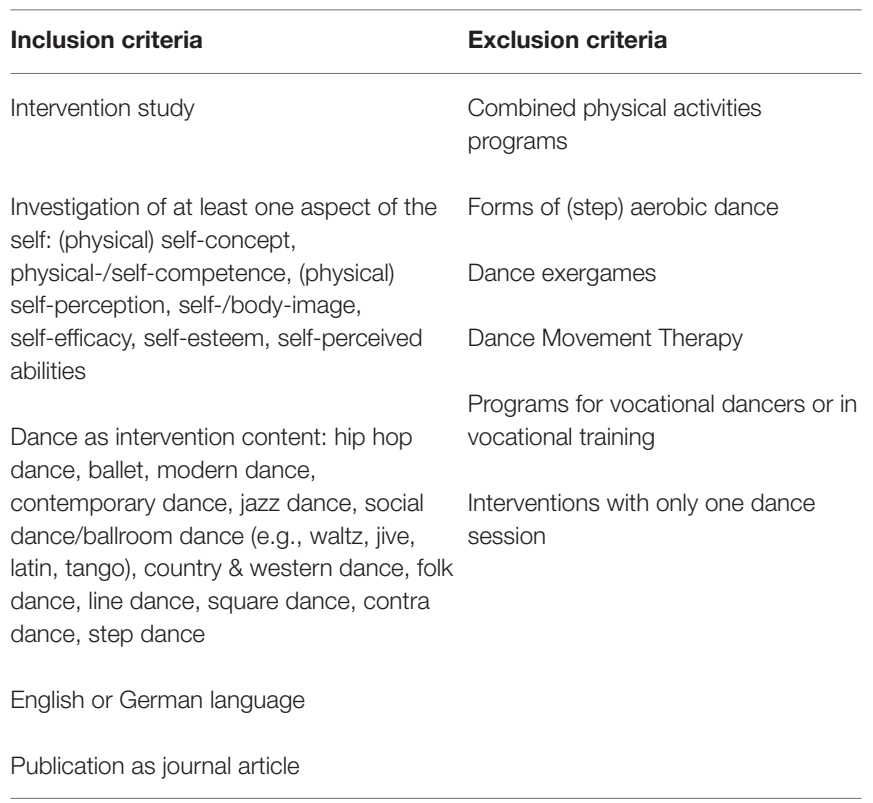

as "Dance Movement Therapy (DMT)" were also excluded. DMT is an internationally accepted body-oriented form of psychotherapy (not every dance intervention with people with special disorders, e.g., physical disabilities, is likewise a dance movement therapeutic intervention; Schmais and White, 1986; Zitomer and Reid, 2011). We excluded studies including dance workshops for vocational dancers or studies that considered the vocational training itself as an intervention. Dance exergames, e.g., "Dance Dance Revolution (DDR)," were excluded because of the lack of internal orientation concerning movement awareness (next level, break the high-score) and the limitation of movement concerning space, quality and variation of movement patterns due to the frameworks (tapping and stepping on the spot). Moreover, dance provides the opportunity for self-expression and is characterized as an expressive activity. In DDR this inherent characteristic of dance is not of relevance. This also applies for forms of (step) aerobic dance. Furthermore, the main objective of aerobic dance is to train the cardiovascular system and the precise performance of each part of the movement plays a less important role than in dance. Therefore, dance-games as well as aerobic dance forms are less dance but rather an aerobic/fitness and coordination training. The exclusion of forms of aerobic dance is in accordance with the systematic review of Hwang and Braun (2015). The exclusion of studies working with DMT, dance exergames and vocational dancers was performed in the review of Burkhardt and Brennan (2012). Additionally, we excluded one study that offered only one dance session.

\section{Selection Process and Risk of Bias Assessment}

In a first step, two reviewers (TS, CO) independently screened all titles of the extracted references. Potentially relevant studies meeting the eligibility criteria were included. Undefined titles remained, due to the risk of bias. The abstracts of included 
studies were screened using the same procedure. If the abstract information was not sufficient to assess eligibility, references remained for full-text analysis. All included relevant studies were assessed based on their full-text for inclusion or exclusion. Both reviewers carefully documented reasons for exclusion after abstract and full-text screening. Furthermore, one author (TS) screened reference lists and citations of included full-text articles in the databases Scopus, Web of Science and the EBSCOhost sources to identify additional relevant studies. Discrepancies between article selections were resolved after discussion at the end of each step of the selection process. In cases of disagreement we involved a third reviewer (SS). The update search followed the same selection procedure.

\section{Data Extraction}

We developed a data extraction sheet and extracted the following data from the full-text articles:

(i) Study characteristics: citation, author, date of publication, country, journal, study approach and design, data acquisition period

(ii) Population: age, gender, sample size, special disorders/impairments/needs (mental, physical)

(iii) Setting

(iv) Intervention characteristics: intervention content, duration and frequency, control group treatment

(v) Methodology and analytic process

(vi) Reported outcomes and main results

(vii) Barriers and limitations

(viii) Information for assessment of the risk of bias

One author (TS) extracted the data of the full-text articles and a second author (CO) checked the data. If data were missing, we contacted the author for further information. Out of six contacted authors (email to the corresponding author), one responded and provided the missing information.

\section{Analysis and Synthesis}

Due to the heterogeneity of the included studies, options for statistical quantitative analyses and overall synthesis of the research findings were limited. Therefore, we decided to analyze the study results for children/adolescents and adults separately in a narrative summary combined with a thematic analysis by the reported constructs (Dixon-Woods et al., 2005). Additionally, we provide three tables presenting the framework conditions and main results of each selected study by separating qualitative, quantitative and mixed methods studies (see Tables 2-4). Moreover, Table 5 contains the available details of the intervention content of included studies.

\section{Methodological Quality Assessment}

Two reviewers (TS, SS) assessed the methodological quality independently. Initial inter-rater reliability on all assessed studies was moderate for studies with quantitative methodologies $(\chi=0.77)$ and strong for studies with qualitative methodologies $(\chi=0.84)$ (McHugh, 2012). Discrepancies were solved through discussion or by referring to a third reviewer (CO). For assessing the quality of studies with qualitative measures we used the
"Checklist for Qualitative Research" provided by the Joanna Briggs Institute (JBI) (Lockwood et al., 2015). To assess the quality of studies with quantitative methodologies we used the "Quantitative Research Assessment Tool” provided by the Child Care and Early Education Research Connections (CCEERC) ${ }^{2}$ Most of the assessment tools include criteria that can hardly be fulfilled in a teaching context, e.g., "Performance Bias": Blinding of participants and personnel ${ }^{3}$ For that reason, we chose a tool with an educational background (as many of the identified studies took place in an educational setting). Quantitative studies were rated on 11 questions using the following scale: $1,0,-1$, not applicable. A question concerning the ethical approval was added in the quantitative assessment tool to account for completeness (Q 12). The adapted tool is part of the Supplementary Material. Additionally, we calculated the mean of the ratings for each quantitative study. Qualitative studies were rated on 10 questions using the following scale: yes, no, unclear, not applicable. The results of the appraisal for each study are presented in Table 6 for qualitative studies and in Table 7 for quantitative studies. Table 7 functions as a summary table, which highlights important quality criteria like sample size, effect size measures, randomization and control. A table with the exhaustive results of the quality assessment in quantitative studies is provided in the supplementary files (see Table A1 in Supplementary Material). The tables should be considered in interpreting the study findings. We did not exclude studies based on poor methodological quality. The respective studies provide important information for further research concerning research desiderata.

\section{RESULTS}

Figure 1 shows the number of extracted references and exclusion/inclusion numbers for each stage of the screening and selection process. Reasons for exclusion after reading the full papers are listed.

The search yielded 9,609 initial hits. After removing duplicates and after screening titles and abstracts, we retrieved 67 articles in full-text. Twenty-two studies met all criteria. Further reference screening yielded no additional studies that met all inclusion criteria. An update search in March 2017 yielded two additional relevant studies. In the end, 24 studies were included in the analysis.

Ten out of 17 quantitative studies report positive effects on various aspects of the self: body-related perceptions (5 out of 8 ) (Blackman et al., 1988; Aşçi, 2002, 2009; Studer-Lüthi and Züger, 2012; Soares Costa de Mendonça et al., 2015), self-esteem (3 out of 6) (Connolly et al., 2011; Pinniger et al., 2013a; Soares Costa de Mendonça et al., 2015), self-efficacy (2 out of 5) (Romero, 2012; Pinniger et al., 2013c), self-concept/self-image (1 out of

\footnotetext{
${ }^{2}$ Quantitative Research Assessment Tool provided by the Child Care and Early Education Research Connections (CCEERC). Available online at: https://www. researchconnections.org/content/childcare/understand/research-quality.html.

${ }^{3}$ The Cochrane Collaboration. Cochrane Handbook for Systematic Reviews of Interventions. Version 5.1.0. Available online at: http://handbook-5-1.cochrane. org/.
} 


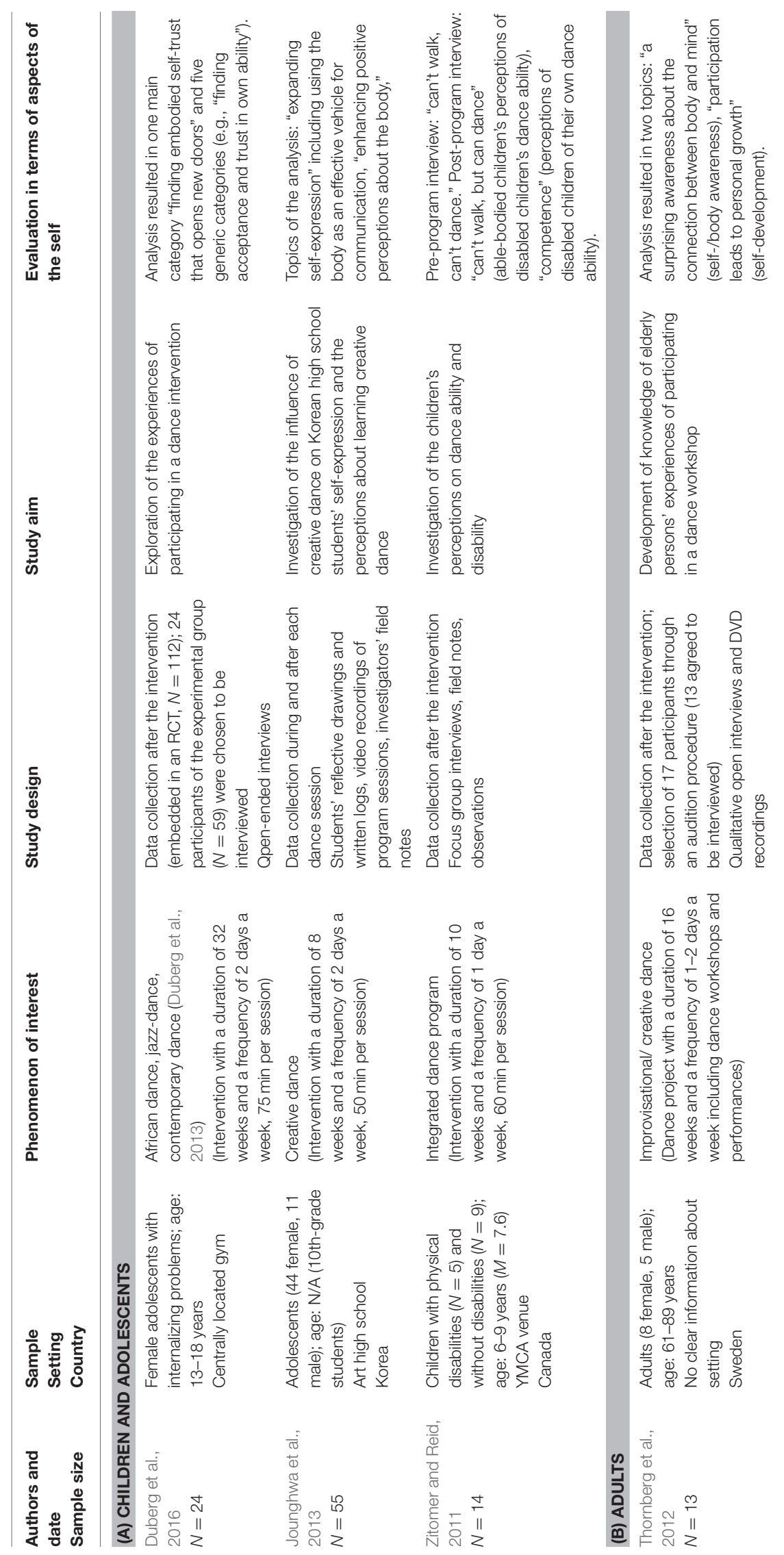




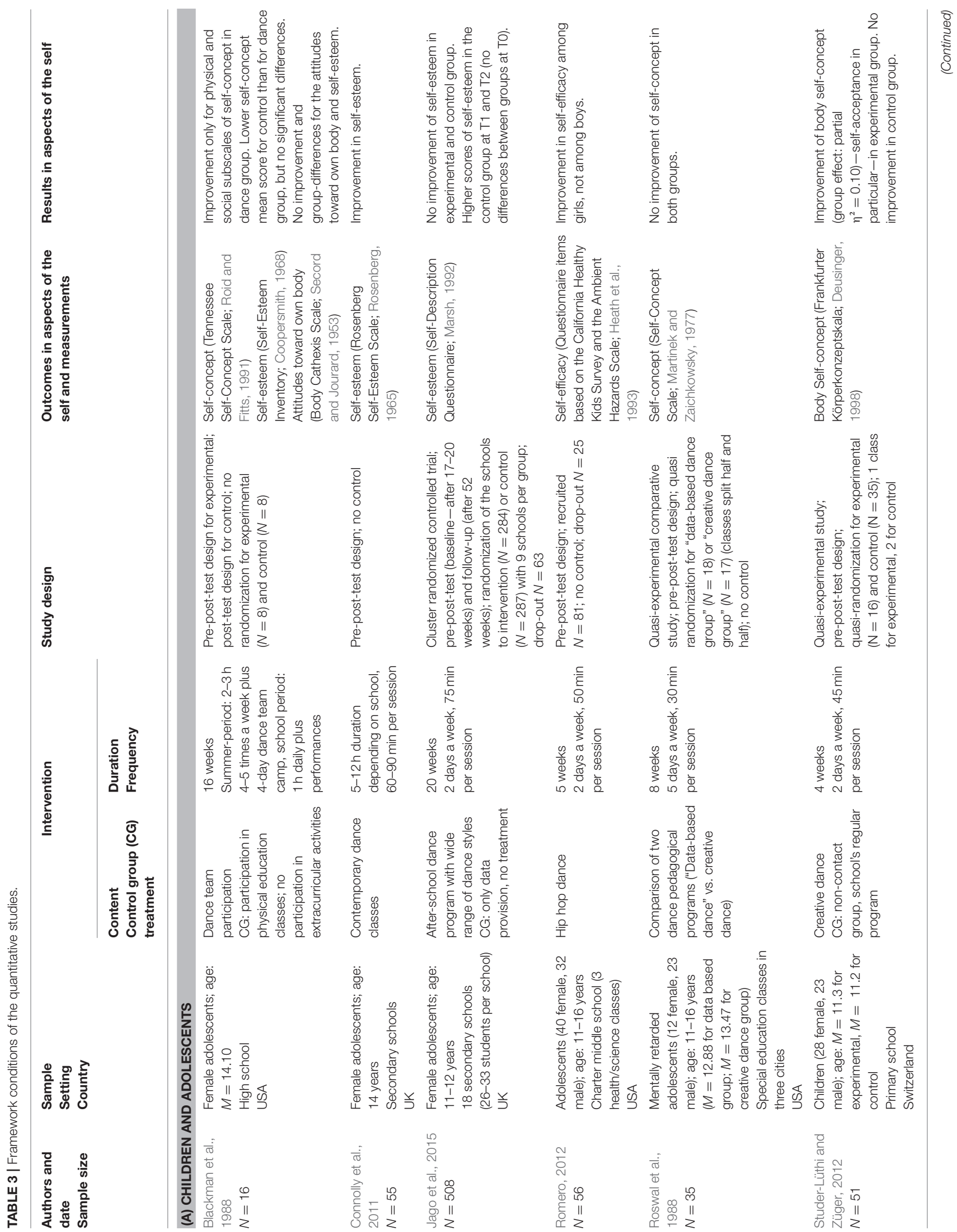




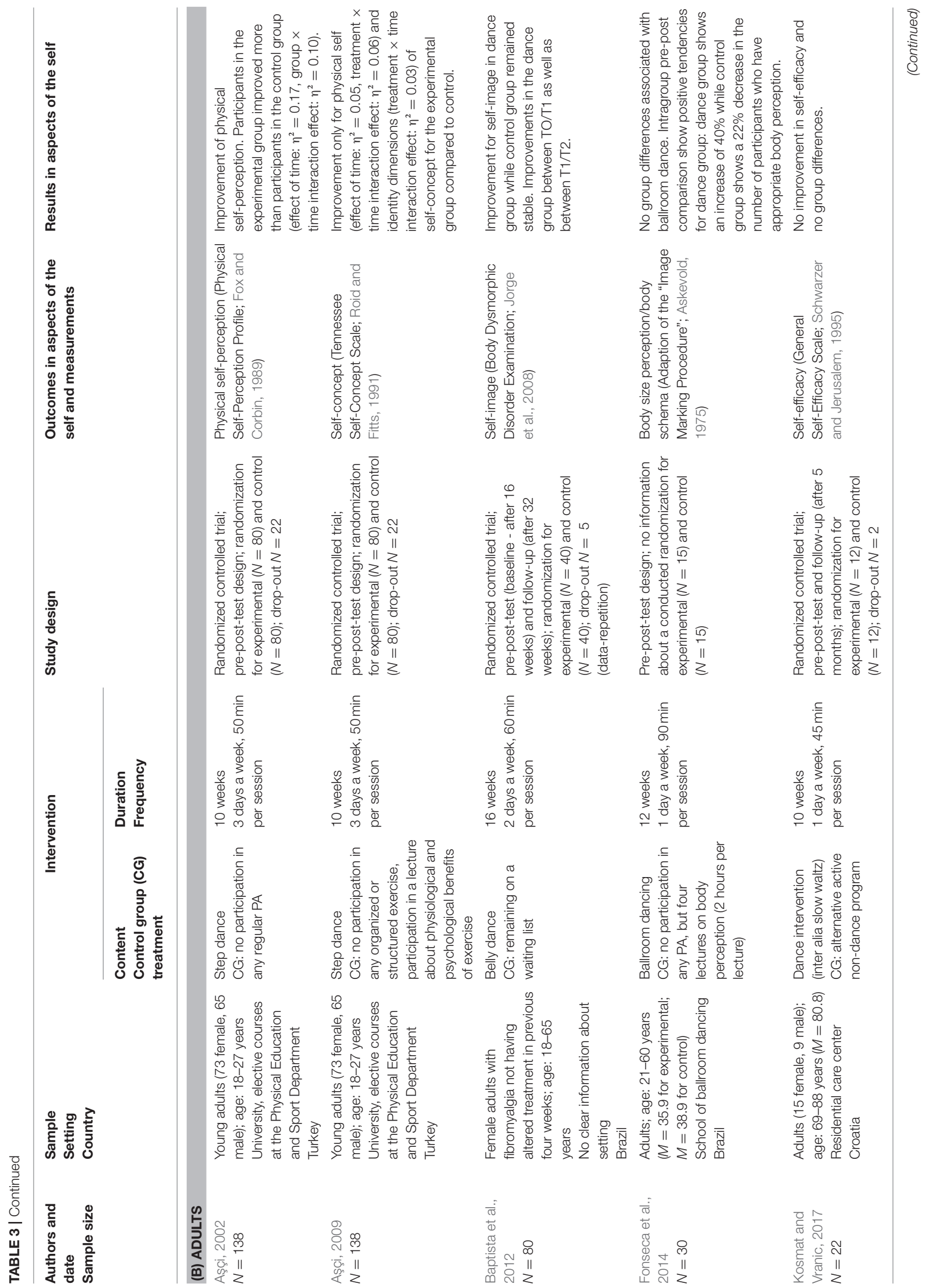




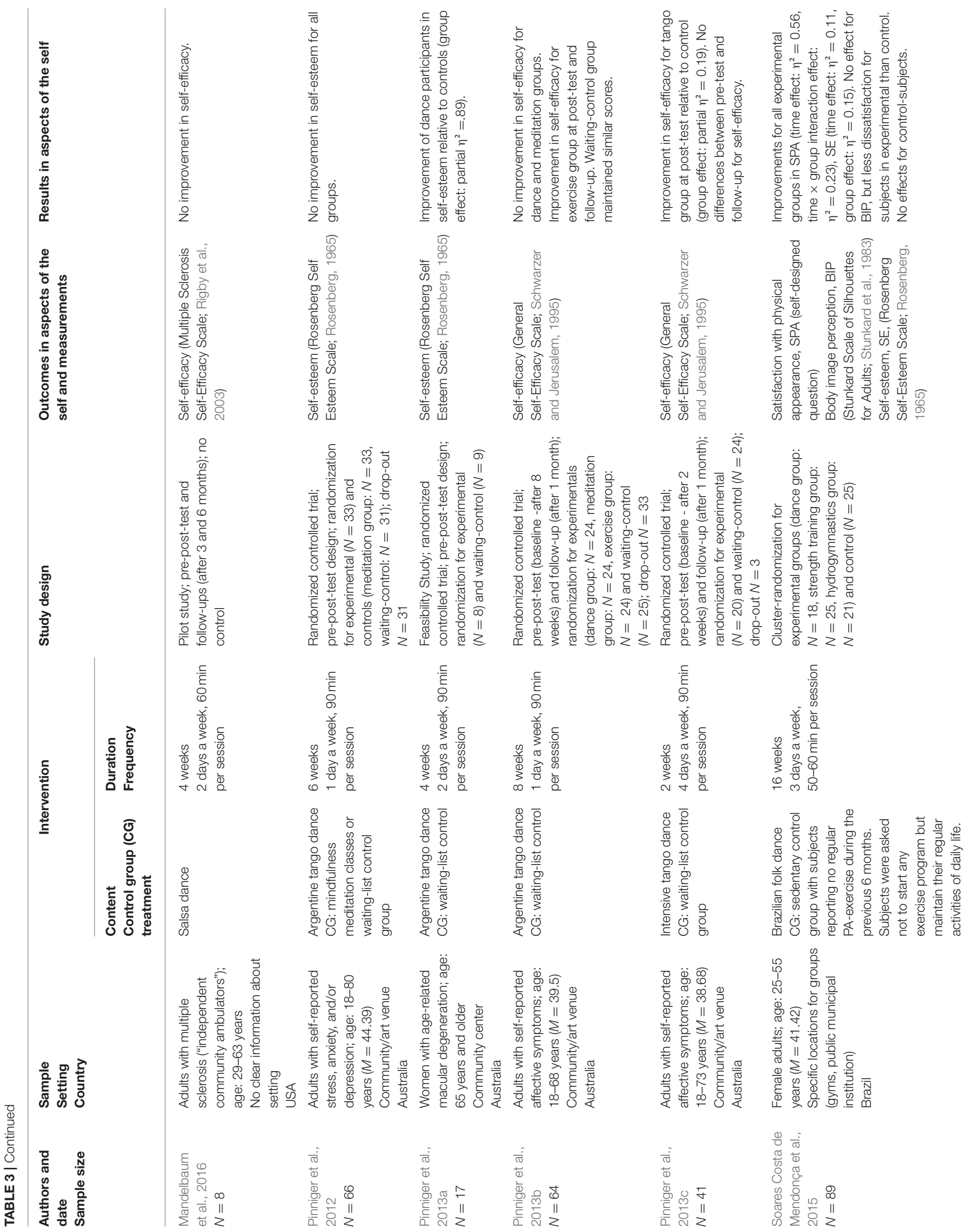




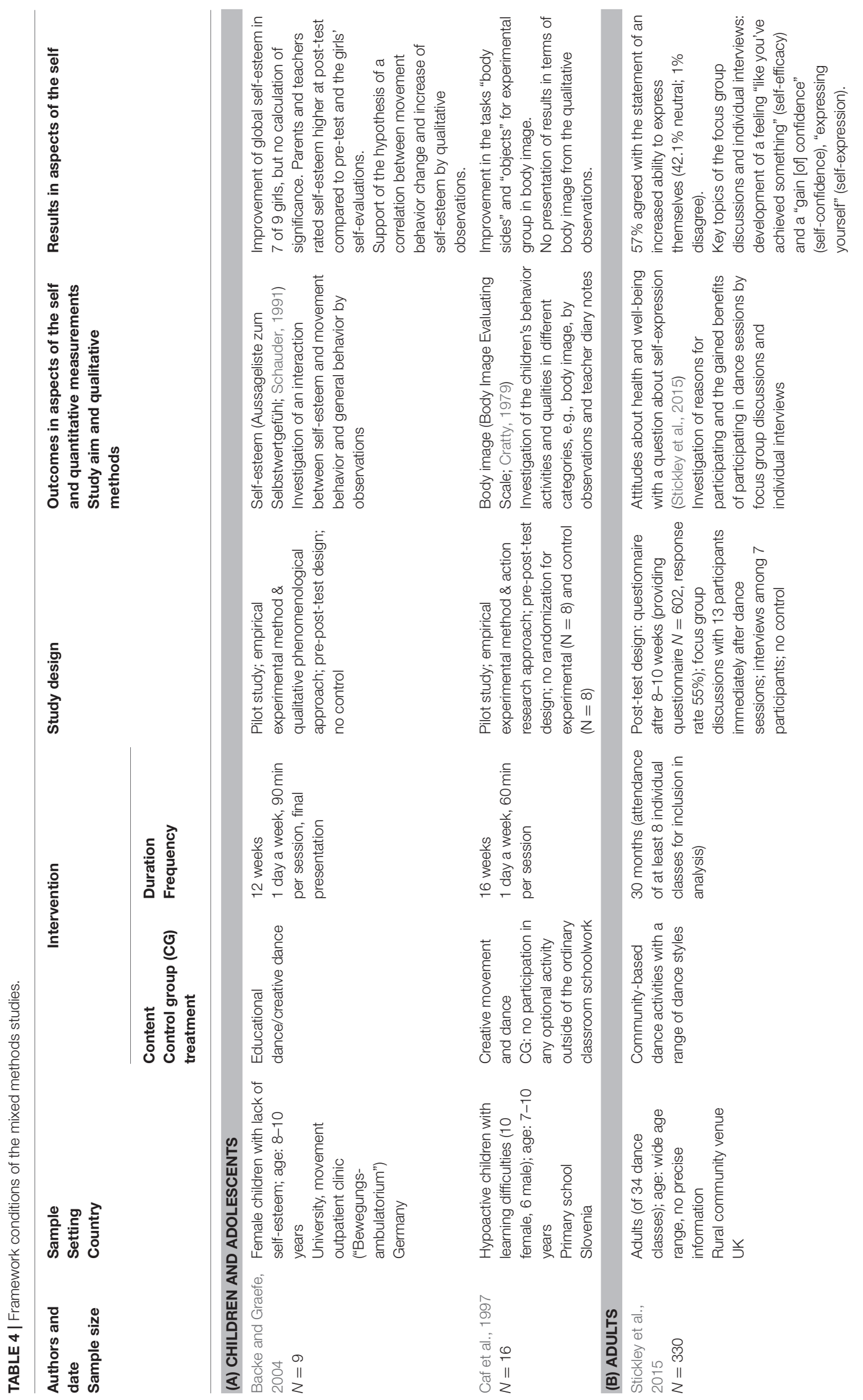



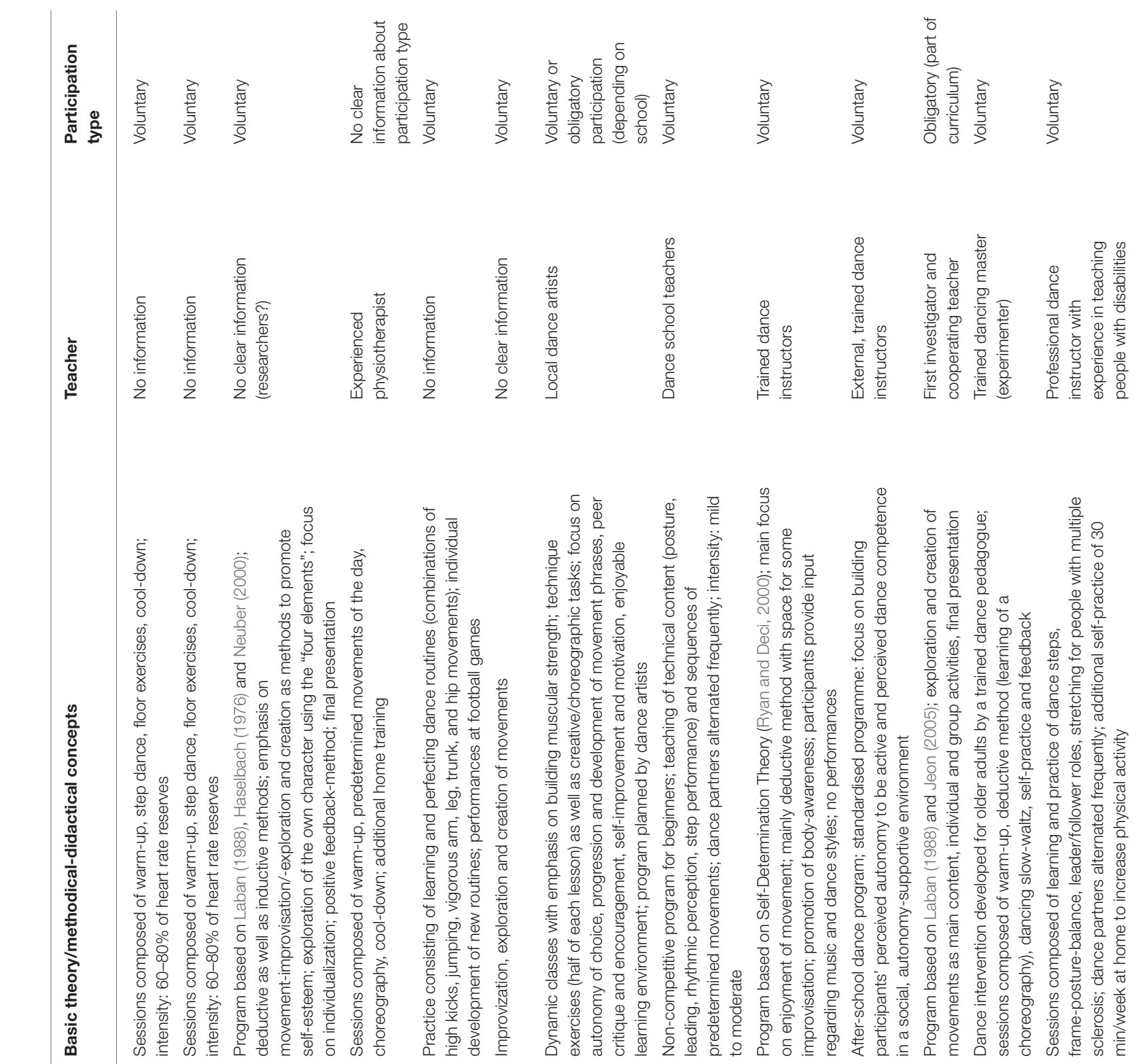

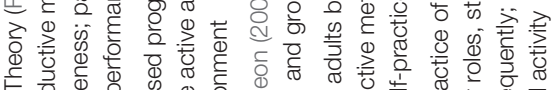

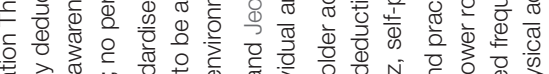

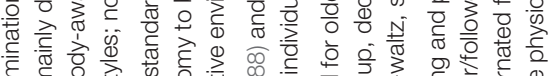

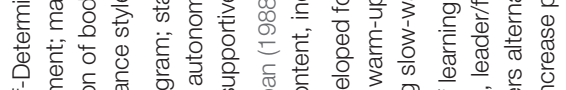

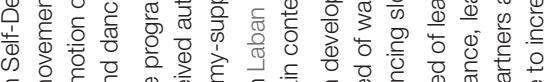

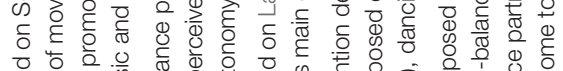

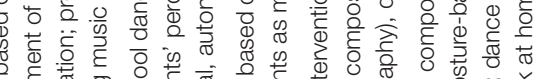

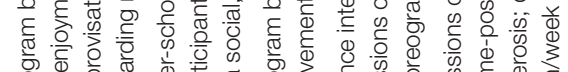

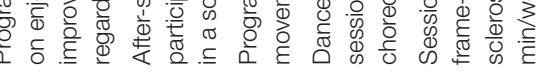

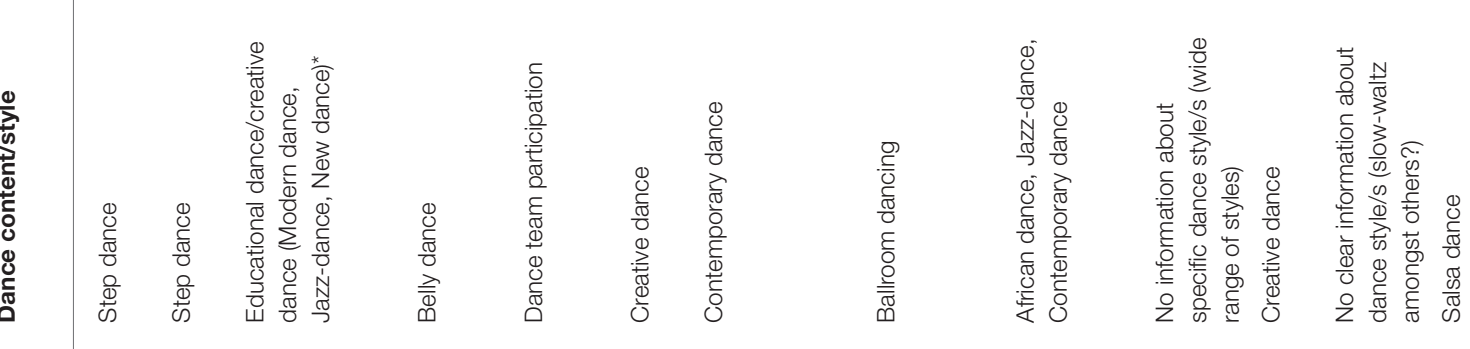




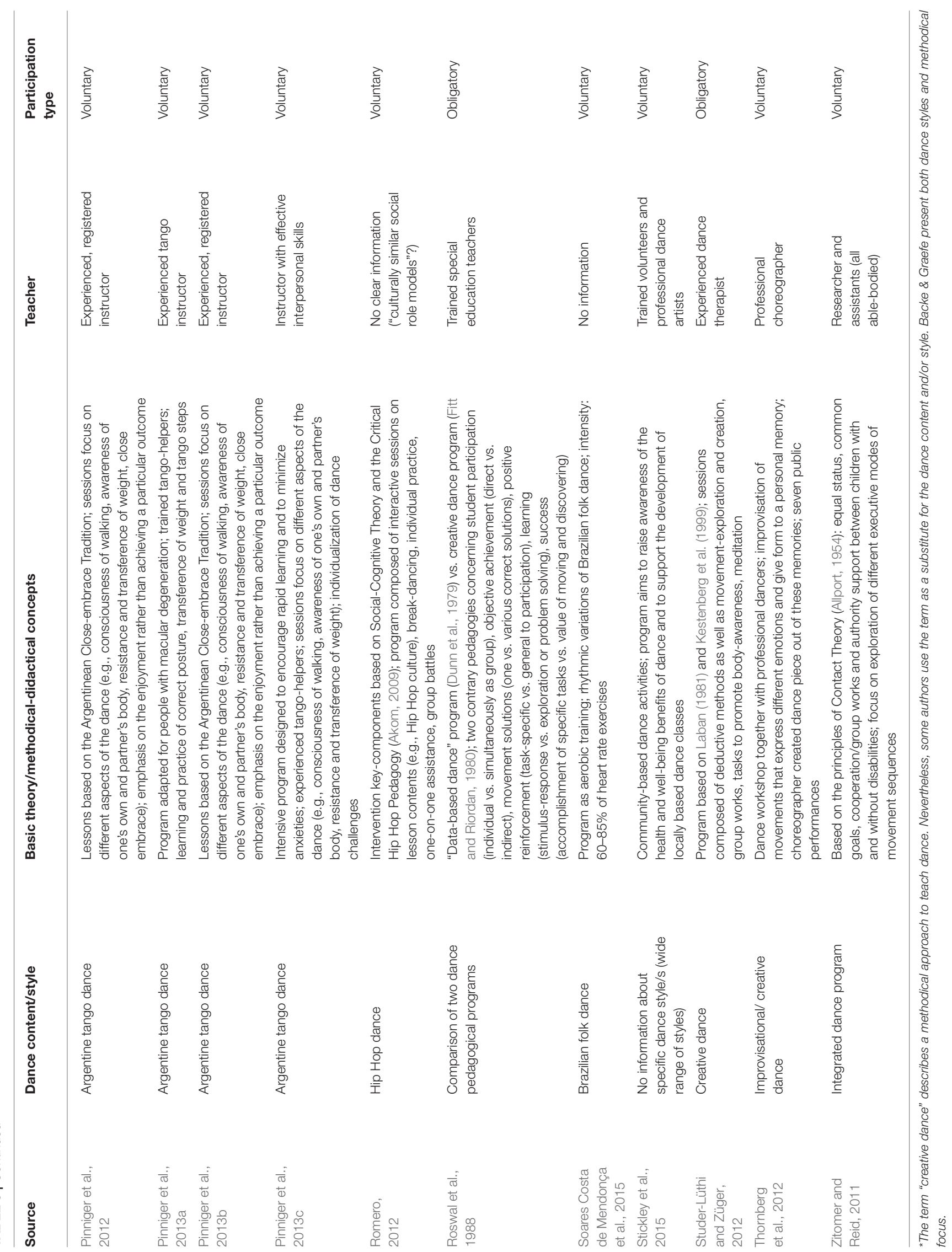


TABLE 6 | Quality of studies with qualitative methodologies (4 qualitative, 3 mixed).

\begin{tabular}{|c|c|c|c|c|c|c|c|c|c|c|}
\hline Source & Q1 & Q2 & Q3 & Q4 & Q5 & Q6 & Q7 & Q8 & Q9 & Q10 \\
\hline \multicolumn{11}{|c|}{ (A) CHILDREN AND ADOLESCENTS } \\
\hline Backe and Graefe, 2004 & No & No & Yes & No & No & Yes & No & No & No & No \\
\hline Caf et al., 1997 & No & Unclear & Yes & No & Unclear & Yes & Unclear & No & No & No \\
\hline Duberg et al., 2016 & Yes & Yes & Yes & Yes & Yes & Yes & Yes & Yes & Yes & Yes \\
\hline Jounghwa et al., 2013 & Yes & Yes & Yes & Yes & Yes & No & No & Yes & No & Yes \\
\hline Zitomer and Reid, 2011 & Yes & Yes & Yes & Yes & Yes & Yes & Unclear & Yes & Yes & Yes \\
\hline \multicolumn{11}{|l|}{ (B) ADULTS } \\
\hline Stickley et al., 2015 & No & No & Yes & Yes & No & No & No & Yes & Yes & Yes \\
\hline Thornberg et al., 2012 & Yes & Yes & Yes & Yes & Yes & No & Unclear & Yes & Yes & Yes \\
\hline
\end{tabular}

Q1: Is there congruity between the stated philosophical perspective and the research methodology?

Q2: Is there congruity between the research methodology and the research question or objectives?

Q3: Is there congruity between the research methodology and the methods used to collect data?

Q4: Is there congruity between the research methodology and the representation and analysis of data?

Q5: Is there congruity between the research methodology and the interpretation of results?

Q6: Is there a statement locating the researcher culturally or theoretically?

Q7: Is the influence of the researcher on the research, and vice-versa, addressed?

Q8: Are the participants, and their voices, adequately represented?

Q9: Is the research ethical according to current criteria or, for recent studies, and is there evidence of ethical approval by an appropriate body?

Q10: Do the conclusions drawn in the research report flow from the analysis, or interpretation, of the data?

4) (Baptista et al., 2012). All four qualitative studies point out positive development in different aspects of the self as one topic of their analyses: body-related perceptions (Jounghwa et al., 2013), self-trust (Duberg et al., 2016), self-expression (Jounghwa et al., 2013), perception of dance-abilities (Zitomer and Reid, 2011), self-development (Thornberg et al., 2012), self-/body-awareness (Thornberg et al., 2012). All three mixed methods studies report positive tendencies in terms of aspects of the self either in their quantitative results or in both qualitative and quantitative results: body image (Caf et al., 1997), self-esteem (Backe and Graefe, 2004), self-efficacy (Stickley et al., 2015), self-expression (Stickley et al., 2015), self-confidence (Stickley et al., 2015). The studies investigate different populations: Eleven studies investigate children and adolescents (Blackman et al., 1988; Roswal et al., 1988; Caf et al., 1997; Backe and Graefe, 2004; Connolly et al., 2011; Zitomer and Reid, 2011; Romero, 2012; Studer-Lüthi and Züger, 2012; Jounghwa et al., 2013; Jago et al., 2015; Duberg et al., 2016). Thirteen studies examine an adult sample (Aşçi, 2002, 2009; Baptista et al., 2012; Pinniger et al., 2012, 2013a,b,c; Thornberg et al., 2012; Fonseca et al., 2014; Soares Costa de Mendonça et al., 2015; Stickley et al., 2015; Mandelbaum et al., 2016; Kosmat and Vranic, 2017). Eleven studies investigate a population with physical or mental disorders (Roswal et al., 1988; Caf et al., 1997; Backe and Graefe, 2004; Zitomer and Reid, 2011; Baptista et al., 2012; Pinniger et al., 2012, 2013a,b,c; Duberg et al., 2016; Mandelbaum et al., 2016). Over half of the studies are conducted in Europe and North America. Eighteen out of 24 studies were published later than 2010. Overall, the included studies are characterized by a variety of intervention contents and timeframes, research designs/approaches and outcome measures. Due to the studies' heterogeneity and the assumption that specific interventions may have different effects on samples of different age groups the results for children/adolescents and adults are analyzed separately.

\section{Dance Interventions in Children and Adolescents \\ Population}

Seven studies investigate a population of adolescents (age-range 11-18 years) (Blackman et al., 1988; Roswal et al., 1988; Connolly et al., 2011; Romero, 2012; Jounghwa et al., 2013; Jago et al., 2015; Duberg et al., 2016). Four studies investigate a sample of children (age-range 6-11 years) (Caf et al., 1997; Backe and Graefe, 2004; Zitomer and Reid, 2011; Studer-Lüthi and Züger, 2012). Five out of the eleven studies examine a population with special disorders, e.g., mental retardation, physical disabilities (Roswal et al., 1988; Caf et al., 1997; Backe and Graefe, 2004; Zitomer and Reid, 2011; Duberg et al., 2016). Five studies have an all-female sample (Blackman et al., 1988; Backe and Graefe, 2004; Connolly et al., 2011; Jago et al., 2015; Duberg et al., 2016). More than half of the studies examine a sample size of 9-35 participants (Blackman et al., 1988; Roswal et al., 1988; Caf et al., 1997; Backe and Graefe, 2004; Zitomer and Reid, 2011; Duberg et al., 2016). Four studies investigate a sample of 51 to 72 participants (Connolly et al., 2011; Romero, 2012; Studer-Lüthi and Züger, 2012; Jounghwa et al., 2013). One study examines a sample of 508 female adolescents (Jago et al., 2015).

\section{Setting}

The majority of the studies with a sample of children and adolescents are located in school settings. Five of the eight studies in a school setting take place at secondary schools (Blackman et al., 1988; Connolly et al., 2011; Romero, 2012; Jounghwa et al., 2013; Jago et al., 2015), two at primary schools (Caf et al., 1997; Studer-Lüthi and Züger, 2012) and one intervention is conducted in special education classes (Roswal et al., 1988). Two further studies examining children with special disorders take place at a community venue (Zitomer and Reid, 2011) or at a university (Backe and Graefe, 2004). Another intervention is located at a 
TABLE 7 | Summary of the studies' quality with quantitative methodologies (17 quantitative, 3 mixed).

\begin{tabular}{|c|c|c|c|c|c|}
\hline Source & Sample size & Control group? & Randomization? & Effect size measures? & Overall quality \\
\hline \multicolumn{6}{|l|}{ (A) CHILDREN AND ADOLESCENTS } \\
\hline Backe and Graefe, 2004 & 9 & No & No & No & $\downarrow$ \\
\hline Baptista et al., 2012 & 80 & Yes & Yes & No & $\uparrow$ \\
\hline Blackman et al., 1988 & 16 & Yes, but no pre-test for control & No & No & $\rightarrow$ \\
\hline Caf et al., 1997 & 16 & Yes & No & No & $\downarrow$ \\
\hline Connolly et al., 2011 & 55 & No & No & No & $\rightarrow$ \\
\hline Jago et al., 2015 & 508 & Yes & Yes & No & $\uparrow$ \\
\hline Romero, 2012 & 56 & No & No & No & $\rightarrow$ \\
\hline Roswal et al., 1988 & 35 & No & Yes (for two IGs) & No & $\downarrow$ \\
\hline Studer-Lüthi and Züger, 2012 & 51 & Yes & Yes & Yes & $\rightarrow$ \\
\hline \multicolumn{6}{|l|}{ (B) ADULTS } \\
\hline Aşçi, 2002 & 138 & Yes & Yes & Yes & $\uparrow$ \\
\hline Aşçi, 2009 & 138 & Yes & Yes & Yes & $\uparrow$ \\
\hline Fonseca et al., 2014 & 30 & Yes & No information & Yes & $\rightarrow$ \\
\hline Kosmat and Vranic, 2017 & 22 & Yes & Yes & Yes & $\uparrow$ \\
\hline Mandelbaum et al., 2016 & 8 & No & No & No & $\rightarrow$ \\
\hline Pinniger et al., 2012 & 66 & Yes & Yes & Yes & $\uparrow$ \\
\hline Pinniger et al., 2013a & 17 & Yes & Yes & Yes & $\rightarrow$ \\
\hline Pinniger et al., 2013b & 64 & Yes & Yes & Yes & $\uparrow$ \\
\hline Pinniger et al., 2013c & 41 & Yes & Yes & Yes & $\uparrow$ \\
\hline Soares Costa de Mendonça et al., 2015 & 89 & Yes & Yes & Yes & $\rightarrow$ \\
\hline Stickley et al., 2015 & 330 & No & No & No & $\downarrow$ \\
\hline
\end{tabular}

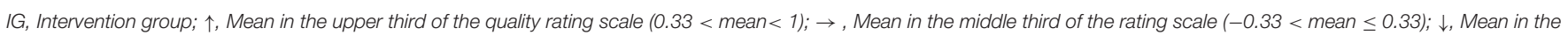
lower third of the rating scale $(-1<$ mean $\leq-0.33)$.

local gym, but the study does not provide information about the initiator (Duberg et al., 2016).

\section{Intervention Content and Timeframe}

The interventions choose different dance styles and contents respectively. Five studies investigate the effects of creative dance programs, including the two studies in primary schools (Roswal et al., 1988; Caf et al., 1997; Backe and Graefe, 2004; Studer-Lüthi and Züger, 2012; Jounghwa et al., 2013). One study compares a creative dance program to a "Data-based dance program" (Roswal et al., 1988). Other intervention contents are hip hop dance (Romero, 2012), contemporary dance (Connolly et al., 2011), an integrated dance program (Zitomer and Reid, 2011) and the participation in a school dance team (Blackman et al., 1988). One study offers various dance styles (African dance, jazzdance, contemporary dance) (Duberg et al., 2016). One study does not specify the intervention content (Jago et al., 2015). The intervention duration ranges from four (Studer-Lüthi and Züger, 2012) to 32 weeks (Duberg et al., 2016). Frequency ranges from one session a week to daily dance training for the participants in a dance team intervention (Blackman et al., 1988). In seven out of 11 studies, participation is purely voluntary (Blackman et al., 1988; Caf et al., 1997; Backe and Graefe, 2004; Zitomer and Reid, 2011; Romero, 2012; Jago et al., 2015; Duberg et al., 2016).

\section{Research Approach and Design}

The studies use different research approaches and designs. Two studies are quasi or rather cluster randomized controlled trials with pre- and post-testing (Studer-Lüthi and Züger, 2012; Jago et al., 2015). One of them includes follow-up measures (Jago et al., 2015). Two studies are non-randomized controlled trials, but with different research approaches [quantitative (Blackman et al., 1988), mixed methods (Caf et al., 1997)] and measurement timeframes, as one study lacks a pretest of the control group (Blackman et al., 1988). Furthermore, there exists one study with a quasi-experimental comparative design without having a nondance control group (Roswal et al., 1988). Control groups are absent in two additional studies with quantitative methodologies (pre-post-test) (Connolly et al., 2011; Romero, 2012). A mixed methods pilot study lacks a control group, too (Backe and Graefe, 2004). Three studies follow a purely qualitative approach (Zitomer and Reid, 2011; Jounghwa et al., 2013; Duberg et al., 2016). They work with interviews, field notes, observations, video recordings, reflective drawings, and written logs.

\section{Investigated Aspects of the Self and Results}

Different aspects of the self are identified as main topics in studies with qualitative methodologies. The participants report positive changes in terms of self-trust in their abilities (Duberg et al., 2016) and in terms of the perceptions of dance ability (Zitomer and Reid, 2011). Moreover, one study highlights an enhancement in self-expression and positive perceptions about the body (Jounghwa et al., 2013).

Studies with quantitative methodologies investigate different aspects of the self and yield different effects. Two studies investigate outcomes that can be summarized as "body-related 


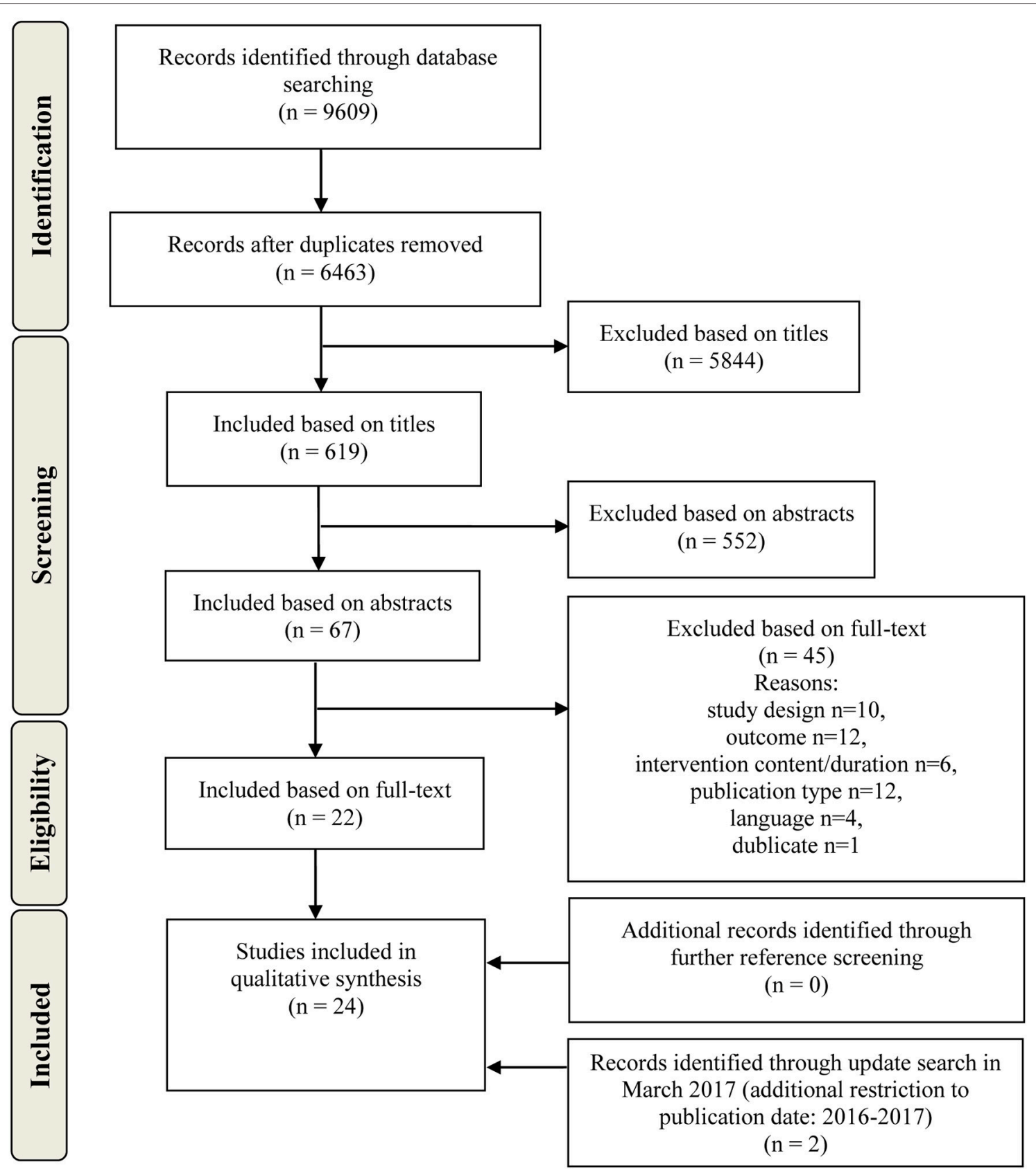

FIGURE 1 | Flow chart of the search and study selection process.

perceptions" and both report positive effects on body self-concept (Blackman et al., 1988; Studer-Lüthi and Züger, 2012). However, one of them does not find positive effects on attitudes toward one's own body (Blackman et al., 1988). Three studies investigate the effects of dance on self-esteem with inconsistent findings. One study reports positive effects (Connolly et al., 2011). Two studies do not find a positive effect (Blackman et al., 1988) or report negative development of self-esteem in the experimental and control group (Jago et al., 2015). Two studies analyze the effects of dance interventions on self-concept (Blackman et al.,
1988; Roswal et al., 1988). Both miss out positive effects of the overall construct, but one of them reports an improvement of the physical and social subscale of self-concept (Blackman et al., 1988). Another study confirms a positive effect of hip hop dance on self-efficacy only for girls, not for boys (Romero, 2012).

Two studies chose a mixed methods approach. One study presents positive changes of the children's movement behavior (expansion in the use of space and the dynamic nature of movement) in the qualitative observations (Backe and Graefe, 2004). Positive tendencies in the quantitative measures in terms 
of self-esteem are associated with the qualitative findings as the progress in movement behavior is seen as an expression of an increased self-esteem (Backe and Graefe, 2004). Nevertheless, the authors do not calculate significance levels. Another study reports positive effects on subscales of body image but does not present results of the qualitative analysis in terms of aspects of the self (Caf et al., 1997).

\section{Study Quality}

The Tables 6, 7 inform about the fulfillment of important quality criteria. The detailed ratings for each quantitative study are presented in Table A1 in Supplementary Material.

Five studies work with qualitative or mixed methods approaches. Three of them (Zitomer and Reid, 2011; Jounghwa et al., 2013; Duberg et al., 2016) meet at least two thirds of the criteria of the methodological assessment tool for qualitative studies. The study conducted by Duberg et al. fulfills all criteria (Duberg et al., 2016). Two studies meet two out of ten criteria (Caf et al., 1997; Backe and Graefe, 2004). All studies show congruity between the research methodology and the methods used to collect data. In contrast, most of the studies fail to address clearly the influence of the researcher on the research, and vice versa. Additionally, three out of five studies do not provide information about ethical considerations (Caf et al., 1997; Backe and Graefe, 2004; Jounghwa et al., 2013).

Eight studies work with quantitative measures. The methodological quality for most of the studies (Blackman et al., 1988; Roswal et al., 1988; Caf et al., 1997; Backe and Graefe, 2004; Connolly et al., 2011; Romero, 2012; StuderLüthi and Züger, 2012) ranges in the lower and middle third of the quality assessment scale, with mean values ranging from -0.5 to 0.17 . One study is in the upper third with a mean value of 0.58 (Jago et al., 2015). Major reasons for low ratings are small samples, missing coefficients or standard errors for the main effect variables as well as missing information about response-/attrition rates and the handling of missing data. Only one study provides results of effect sizes measures. Five out of eight studies present means and standard deviations/errors for all numeric variables. Two studies select the participants randomly. Half of the studies present statements according to ethical approval in an appropriate way. Most of the studies describe their main variables and concepts of interest and fulfill the operationalization of these concepts.

\section{Dance Interventions in Adults Population}

Thirteen studies investigate the effects of dance in an adult population. The studies are based on twelve data sets. A wide age range characterizes more than 50 percent of the samples. However, three studies investigate a sample of older adults (Thornberg et al., 2012; Pinniger et al., 2013a; Kosmat and Vranic, 2017). Contrary, Aşçi's studies examine a sample of young adults with an age range of 18-27 years (Aşçi, 2002, 2009). Six studies investigate a population with special disorders (Baptista et al., 2012; Pinniger et al., 2012, 2013a,b,c; Mandelbaum et al., 2016). Six studies investigate a sample ranging from 8 to 41 participants (Thornberg et al., 2012; Pinniger et al., 2013a,c; Fonseca et al., 2014; Mandelbaum et al., 2016; Kosmat and Vranic, 2017). Four studies show a sample size of 64 up to 89 participants (Baptista et al., 2012; Pinniger et al., 2012, 2013b; Soares Costa de Mendonça et al., 2015). Moreover, Aşçi's studies investigate 138 participants (Aşçi, 2002, 2009). Stickley et al. conduct a study with 330 participants consisting of people from 34 different dance classes (Stickley et al., 2015).

\section{Setting}

The studies are located in different settings. Six studies take place at community/public or art venues (Pinniger et al., 2012, 2013a,b,c; Soares Costa de Mendonça et al., 2015; Stickley et al., 2015) and one study is located in a school for ballroom dancing (Baptista et al., 2012). Another study is conducted in a residential care center (Kosmat and Vranic, 2017). Three studies do not provide clear information about the setting of the dance intervention (Baptista et al., 2012; Thornberg et al., 2012; Mandelbaum et al., 2016). The review found two studies within a university setting (Aşçi, 2002, 2009).

\section{Intervention Content and Timeframe}

Almost half of the studies offer social dance as intervention content (Pinniger et al., 2012, 2013a,b,c; Fonseca et al., 2014; Mandelbaum et al., 2016). Five of them investigate a population with special disorders (Pinniger et al., 2012, 2013a,b,c; Mandelbaum et al., 2016). Other interventions choose step dance (Aşçi, 2002, 2009), belly dance (Baptista et al., 2012), Brazilian folk dance (Soares Costa de Mendonça et al., 2015) and improvisational/creative dance (Thornberg et al., 2012). Two studies offer a program with various dance styles (Stickley et al., 2015; Kosmat and Vranic, 2017). The interventions show different timeframes. The minimum duration is 2 weeks (Pinniger et al., 2013c). The study conducted by Stickley et al. shows the largest duration (30 months), but the attendance rate for inclusion in analysis is set at a minimum of eight individual classes. There was no information available about the general dance training frequency or the required frequency for inclusion in this study (Stickley et al., 2015). All other studies offer dance in one up to four sessions a week. One study lacks clear information about the type of participation, in all the other studies the participation is voluntary (Baptista et al., 2012).

\section{Research Approach and Design}

Different research approaches and designs can be found. Eight studies are randomized controlled trials (RCTs) with pre-posttesting (Aşçi, 2002, 2009; Baptista et al., 2012; Pinniger et al., 2012, 2013a,b,c; Kosmat and Vranic, 2017), four of them include follow-up measures (Baptista et al., 2012; Pinniger et al., 2013b,c; Kosmat and Vranic, 2017). Furthermore, Soares Costa de Mendonça et al. use a design with three clusterrandomized experimental groups and one control group (Soares Costa de Mendonça et al., 2015). A study undertaken by Costa Fonseca et al. with a pre- and post-test design does not provide information about a conducted randomization for the experimental and control group (Fonseca et al., 2014). 
Mandelbaum et al. conduct a pilot study with a pre- and posttest design and two follow-ups, but do not have a control group (Mandelbaum et al., 2016). Stickley et al. use a mixed methods approach combining a post-test quantitative questionnaire with qualitative interviews and discussions (Stickley et al., 2015). Thornberg et al. conduct a qualitative study and analyze interviews and DVD recordings (Thornberg et al., 2012).

\section{Investigated Aspects of the Self and Results}

The one study, which uses qualitative methodologies, highlights positive development in aspects of the self as main topic of the analysis. The participants report positive changes in terms of self-/body-awareness and self-development (Thornberg et al., 2012).

Different outcomes have been addressed by studies with quantitative methodologies. Three studies investigate bodyrelated perceptions: two studies report a positive effect on physical self-perception (Aşçi, 2002) and satisfaction with physical appearance (Soares Costa de Mendonça et al., 2015). It should be noted that in the study conducted by Soares Costa de Mendonça et al. a positive effect on the satisfaction with physical appearance is found in all active experimental groups (dance, strength training, hydrogymnastics) (Soares Costa de Mendonça et al., 2015). However, the study does not find positive effects on body image perception (Soares Costa de Mendonça et al., 2015). The study results of Fonseca et al. do not show positive effects on body size perception but tendencies that dance can help in gaining an appropriate body perception (Fonseca et al., 2014). Four studies investigate the effects on self-efficacy. An improvement in self-efficacy is stated in one study for the post-test but not for the follow-up measures (Pinniger et al., 2013c). Three studies expose no improvement at the post-test as well as at follow-up (Pinniger et al., 2013b; Mandelbaum et al., 2016; Kosmat and Vranic, 2017). Moreover, three studies investigate self-esteem. Two of them find positive effects on self-esteem for the dance group (Pinniger et al., 2013a; Soares Costa de Mendonça et al., 2015). Again, the study conducted by Soares Costa de Mendonça et al., exposes improvement in self-esteem for all experimental groups (Soares Costa de Mendonça et al., 2015). The third study focusing on self-esteem does not report a positive effect of tango dance (Pinniger et al., 2012). Furthermore, two studies analyze the effect on self-image and self-concept, respectively. The RCT study by Baptista et al. outlines a positive effect on self-image in the dance group, which maintained at follow-up (Baptista et al., 2012). Aşçi investigates self-concept. An overall improvement of self-concept is absent. However, positive effects are reported for physical self and identity dimensions of the self-concept (Aşçi, 2009).

One study choses a mixed methods approach (Stickley et al., 2015). The results of the qualitative analysis indicate a positive impact of dance as the participants report positive development in self-expression, self-efficacy and self-confidence. The quantitative measures support these findings in part as they show positive tendencies in terms of self-expression. However, the study does not provide significance levels.

\section{Study Quality}

The Tables 6, 7 inform about the fulfillment of important quality criteria. The detailed ratings for each quantitative study are presented in Table A1 in Supplementary Material.

Two studies work with qualitative measures. The study conducted by Thornberg et al. fullfills 8 out of 10 criteria of the methodological assessment tool (Thornberg et al., 2012). The study undertaken by Stickley et al. meets half of the criteria (Stickley et al., 2015). Neither study provides a statement locating the researchers culturally or theoretically. Moreover, a clear declaration of the influence of the researcher on the research, and vice versa, is absent.

Twelve studies follow a quantitative approach. The methodological quality of most studies ranges in the middle or upper third of the quality assessment scale, with mean values from 0.25 to 0.75 (Aşçi, 2002, 2009; Baptista et al., 2012; Pinniger et al., 2012, 2013a,b,c; Soares Costa de Mendonça et al., 2015; Mandelbaum et al., 2016; Kosmat and Vranic, 2017). Two studies deviate from the majority as they show mean values of 0.08 (Fonseca et al., 2014) and -0.33 (Stickley et al., 2015). Main reasons for low ratings are small samples as well as missing information about the handling of missing data. Nine studies select their participants in randomized fashion. All studies fullfill the operationalization of concepts and present statements subject to ethical criteria in an appropriate way. Nine studies present results of effect size measures.

\section{DISCUSSION}

This systematic review aimed at giving an overview of studies that investigate the effects of dance interventions on aspects of the participants' self. The results indicate that dance can have positive effects on different aspects of the self in children/adolescents and adults, especially on body-related perceptions. Despite positive findings, evidence for the different aspects is still poor due to the small number of studies on each construct and/or inconsistent findings. The evaluated studies show an overall heterogeneous nature of research designs and methods as well as intervention contents and timeframes. Furthermore, they differ in terms of methodological quality.

\section{Dance Interventions in Children and Adolescents \\ Effects on the Participants' Self}

In the field of body-related perceptions one qualitative study was identified (Jounghwa et al., 2013). The results correspond to theoretical assumptions: dance promotes the ability of selfexpression via the body. Apparently, this positive development is associated with an awareness of numerous opportunities for nonverbal expression through different body movements and with an enhancement of positive perceptions about the body (Jounghwa et al., 2013). Studies with quantitative methodologies investigating body-related perceptions report positive effectswith moderate effect size-on body self-concept (Studer-Lüthi and Züger, 2012) or no significant effects on body image but positive tendencies (Caf et al., 1997). One quantitative 
study reports inconsistent findings concerning body-related perceptions: Blackman et al. do not find improvement of attitudes toward the subject's own body but on the physical subscale of self-concept (Blackman et al., 1988). Overall, these quantitative results rather support the qualitative findings. Furthermore, they support the results found by Burkhardt and Brennan (2012), who identified two studies showing improved body image/attractiveness and physical self-worth through aerobic dance participation in adolescent females. However, as aerobic dance rather focuses on fitness aspects than on the self-expression via the body, a comparison of their results and the results of this review must be interpreted with caution. It remains unclear if an improvement of body-related perceptions arises from physical activity per se or from the specific activity that involves movement to music. The fact that the study results show inconsistent findings on closely linked constructs reflects the complexity of the outcome field. Furthermore, questionnaires differ concerning their scales and items that may be more or less suitable to capture the impact of dance experiences. Question items at a very general level may not be directly transferable to the dance context. Looking at the studies' quality, the qualitative study fulfills seven out of 10 quality criteria and therefore performs well (Jounghwa et al., 2013). The quantitative studies on this outcome range in the lower (Caf et al., 1997) and middle third (Blackman et al., 1988; Studer-Lüthi and Züger, 2012) of the quality rating scale. Nevertheless, one of them fulfills important quality criteria like quasi-randomization, control and the calculation of effect sizes (Studer-Lüthi and Züger, 2012). Summarizing the results of qualitative and quantitative measures, evidence for effects of dance on body-related perceptions is low. Main reasons are the small number of studies and their overall moderate quality. However, the predominant positive impact supports theoretical explanations, since dance is characterized as an activity with an internal orientation including the awareness of the own body in motion (Ullmann, 2001; Gardner et al., 2008).

The review found inconsistent results on effects of dance on self-esteem in young people and thus poor evidence for this outcome. All studies use quantitative methodologies. Two studies report positive effects (Connolly et al., 2011) or no significant effects but positive tendencies (Backe and Graefe, 2004) and two studies show no (Blackman et al., 1988) or negative effects (Jago et al., 2015). Nevertheless, another review points out the positive impact of creative interventions on the self-esteem of children and young people, even if evidence is weak (Bungay and Vella-Burrows, 2013). The review analyses interventions with different forms of performing arts (e.g., music, singing, drama/theater, visual arts, dance) as content. This indicates that dance interventions with a focus on the inherent creative aspects of dance may have the potential to improve self-esteem. In this review, the detected discrepancies of the study findings in terms of self-esteem may be the result of differences concerning the dance interventions. For example, the interventions differ in terms of dance content (only one study shows an emphasis on creative techniques; Backe and Graefe, 2004) and duration. The quality of studies reporting positive effects ranges in the lower (Backe and Graefe, 2004) and middle third (Connolly et al.,
2011) of the rating scale. The studies reporting no or negative effects perform better with ratings in the middle (Blackman et al., 1988) and upper third (Jago et al., 2015) of the rating scale. However, the negative results of the study with the best quality must be interpret with caution due to attendance problems (Jago et al., 2015). Ekeland et al. review the effects of exercise on the self-esteem of children and young people and point out methodological shortcomings, too (Ekeland et al., 2005). Over half of their 25 included studies show a high risk of bias. Hence, achieving high study quality seems to be challenging for various activity intervention studies promoting self-esteem in young people.

Evidence for the effects of dance interventions with young people on self-concept, self-trust, perceptions of the subjects' own abilities and self-efficacy is poor, as the review identified only one or two studies that report results concerning each of these constructs, respectively. However, the positive findings of qualitative studies in terms of self-trust and the perceptions of the subjects' own abilities (Zitomer and Reid, 2011; Duberg et al., 2016) lie close to adjacent research fields: Bungay and Vella-Burrows review the effects of participating in creative activities on health and well-being of children and young people (Bungay and Vella-Burrows, 2013). An increased confidence is the most commonly reported outcome in all studies they review. Moreover, the mentioned studies fulfill all (Duberg et al., 2016) or at least 9 out of 10 (Zitomer and Reid, 2011) quality criteria and thus can serve as an example of qualitative research of high quality in the field.

\section{Dance Intervention Conditions}

Almost half of the samples consist of children and adolescents with special disorders. Out of the five studies, four report positive findings: studies with qualitative methodologies point out positive changes in terms of self-trust (Duberg et al., 2016) and perceptions of dance ability (Zitomer and Reid, 2011) as main topics of their analysis; studies with quantitative methodologies outline effects in subscales of body image (Caf et al., 1997) and no significant effects but positive tendencies in self-esteem (Backe and Graefe, 2004). Three out of five respective studies (Roswal et al., 1988; Caf et al., 1997; Backe and Graefe, 2004) state that they choose creative dance as intervention content. A closer look at the described intervention lessons shows that the two other interventions with participants with special disorders work with creative techniques as well. They offer processes of movement exploration/improvisation (Zitomer and Reid, 2011; Duberg et al., 2016) and cooperative group works giving space to different executive modes based on different physical capacities and interests (Zitomer and Reid, 2011). Creative dance is oriented toward the movement opportunities of the individual person. It pursues exploring movement possibilities and the solving of movement oriented tasks to enrich self-expression (Laban, 1948). Due to the student-centered and non-normed way of understanding and teaching dance, students with certain limitations can possibly experience success and self-efficacy. However, two of these studies - both mixed methods studiesshow substantial methodological shortcomings (Caf et al., 1997; Backe and Graefe, 2004). Hence, creative dance may be an 
appropriate activity for children and adolescent with disorders to enhance certain aspects' of the self, but evidence is still poor.

Moreover, two creative dance interventions with a sample without special disorders report positive effects (Studer-Lüthi and Züger, 2012) or positive findings, revealed from a qualitative analysis, (Jounghwa et al., 2013) regarding aspects of the participants' self as well. Therefore, creative dance may also be an appropriate activity intervention to strengthen personal aspects of children and adolescents without special disorders. As the review identified only two respective studies, evidence is poor as well.

The reviewed intervention studies show different timeframes. Regarding the study results, there seems to be no relation between a certain duration or frequency of dance interventions and their efficacy. This assumption is in accord with the findings of a systematic review in an adjacent research field (Ekeland et al., 2005): Ekeland et al. report that there are few or no differences concerning the results when they excluded the studies with an intervention duration of less than 10 weeks from their analysis. On the contrary, dance interventions that aim to improve physical fitness of young people seem to require a certain minimum timeframe: all respective studies in the review of Burkhardt and Brennan lasted at least 8 weeks and were realized in at least three 45-minute sessions per week (Burkhardt and Brennan, 2012). This appears conclusive, as physical adaptation requires a certain duration and intensity. Positive development in aspects of the self may potentially arise faster. Hence, there seem to be more important influencing factors than the intervention timeframe that may have impact on personal constructs. Especially the influence of the teacher and methodical-didactical concepts may play an important role. However, the only identified study of a comparative nature does not find positive effects on self-concept in both programs (Roswal et al., 1988).

Eight of the studies with children and adolescents take place in a school setting. Most studies conducted in this setting report positive effects in terms of body-related perceptions, self-esteem or self-efficacy determined by their quantitative measures (Blackman et al., 1988; Caf et al., 1997; Connolly et al., 2011; Romero, 2012; Studer-Lüthi and Züger, 2012) or point out positive changes in the ability of self-expression and the perceptions about the body as main topic of their qualitative analysis (Jounghwa et al., 2013). These positive results indicate that school could be a valuable setting for dance interventions. However, this review discovered two critical issues of dance interventions in the school setting. Firstly, we found different participation types. In four studies the participation was purely voluntary. Three of them report positive findings regarding aspects of the self (Blackman et al., 1988; Caf et al., 1997; Romero, 2012). Three studies show a mandatory participation and two of them report positive findings (Studer-Lüthi and Züger, 2012; Jounghwa et al., 2013). One quantitative study investigates a sample with voluntary as well as mandatory participants and outlines positive effects on self-esteem (Connolly et al., 2011). They report that different participation types may have had an impact on intrinsic motivational levels, but it was not possible to separate these two groups for examining group differences.
Moreover, the only study with an overall quality in the upper third of the rating scale has to deal with attendance problems; it was organized as an after-school dance program with voluntary participation (Jago et al., 2015). The critical issue of adherence is discussed by adjacent research fields such as the investigation of the effects of yoga interventions. Büssing et al. mention that the potentially beneficial impact of yoga can be limited by low adherence rates (Büssing et al., 2012). In summary, we are not able to draw a conclusion from the empirical data whether a certain participation type is associated with more positive results. The design of comparative studies could be an approach to answer this question. However, the problems in terms of attendance rates may influence the findings of comparative studies, too. Secondly, we discovered critical issues concerning the study design and quality. None of the studies in a school setting is organized as a randomized controlled trial. We identified only three studies with quasi or cluster randomized groups (Roswal et al., 1988; Studer-Lüthi and Züger, 2012; Jago et al., 2015). Moreover, three out of seven studies with quantitative measures lack a control group (Roswal et al., 1988; Connolly et al., 2011; Romero, 2012). The samples consist of 40 participants on average (excluding one study with an exceptional sample size of $N=508$ ). Overall, study quality of studies with quantitative measures ranges mainly in the lower and middle third of the rating scale. The review found no single quantitative study with a high study quality in a school setting and an applicable assessment of the effects of dance on aspects of the self (Jago et al., 2015) ${ }^{4}$. Looking at the studies with a qualitative approach, we found one study that meets seven out of ten quality criteria (Jounghwa et al., 2013) and one study with only two criteria fulfilled (Caf et al., 1997). In view of these results, achieving high study quality seems to be challenging in particular in a school setting. Studer-Luethi and Zueger as well as Burkhardt and Brennan mention that those studies have to deal with certain framework conditions that may place some limits for research (Burkhardt and Brennan, 2012; Studer-Lüthi and Züger, 2012). Nevertheless, school could function as a valuable setting due to the relative heterogeneity of the potential sample. All potential children and adolescents can be reached. Moreover, it offers the possibility of mandatory participation in a certain intervention, for example through an embedding in physical education lessons. Given the fact that national curricula demand the promotion of constructs like the students' self-confidence, self-awareness and self-competence ${ }^{5}$, additional high-quality research on dance interventions in the school setting is needed to examine the assumption that dance

\footnotetext{
${ }^{4}$ Jago et al. state that it is not possible to use the data from their project to assess the effects of attending dance programmes on self-esteem or other health outcomes. Only one-third of the intervention participants met the pre-set attendance criteria. ${ }^{5}$ Staatsinstitut für Schulqualität und Bildungsforschung München. Lehrplan für das Gymnasium in Bayern. Fachprofil Sport. Retrieved from http://www. isb-gym8-lehrplan.de/contentserv/3.1.neu/g8.de/index.php?StoryID=26406; Australian Curriculum Assessment and Reporting Authority. Introduction of the Australian F-10 curriculum. Retrieved from https://www.australiancurriculum. edu.au/f-10-curriculum/general-capabilities/personal-and-social-capability; Ministry of Education Ontario. The Ontario Curriculum Grades 1 to 8. Health and Physical Education. Retrieved from http://www.edu.gov.on.ca/eng/curriculum/ elementary/health1to8.pdf.
} 
strengthens personal aspects. With regard to study design and quality in different settings, only three studies are quasi or cluster randomized controlled trials with pre- and post-testing (Roswal et al., 1988; Studer-Lüthi and Züger, 2012; Jago et al., 2015). Authors of two other systematic reviews concerning performing arts and recreational dance interventions with young people (Daykin et al., 2008; Burkhardt and Brennan, 2012) also report an underrepresentation of randomized controlled trials. Furthermore, only three out of eight studies with quantitative measures have a control group (Caf et al., 1997; Studer-Lüthi and Züger, 2012; Jago et al., 2015). The reviewed studies of Daykin et al. perform little better (Daykin et al., 2008): six out of nine quantitative studies are identified as controlled studies; three of them are identified as randomized controlled trials. One possible reason for the higher rate of controlled and randomized studies may be that they included only interventions outside the usual curriculum. We found only one study with follow-up measures (Jago et al., 2015). This is similar to the findings of Ekeland et al. as their reviewed exercise intervention studies with a sample of children or young people lack follow-up measures (Ekeland et al., 2005). Thus, the implementation of rigorous and complex research designs seems to be a general challenge in exercise and dance intervention studies with a sample of young people, which aim to promote aspects of the self. None of the controlled studies in this review has an active control group. Therefore, the studies cannot answer the question of whether the intervention focus on dance is the reason for the reported effects. Additionally, only one out of five studies with qualitative measures clearly addresses the influence of the researcher on the research and vice versa (see Table 6, Q7). This seems to be important in particular when the role of the researcher and the teacher coincide. These issues are also emphasized by Daykin et al. as most of their reviewed performing arts intervention studies do not include a reflexive discussion of the relationships between researcher and participants (Daykin et al., 2008).

\section{Dance Interventions in Adults Effects on the Participants' Self}

Overall, the results indicate that dance interventions can have positive impact on body-related perceptions of adults: a qualitative study points out that the participants benefit in terms of bodyawareness (Thornberg et al., 2012). The fact that quantitative studies report positive effects-with small or medium effect sizes-on physical self-perception (Așçi, 2002, 2009) and positive tendencies in body size perception support this finding (Fonseca et al., 2014), while one study outlines inconsistent results (Soares Costa de Mendonça et al., 2015). The positive trend is comparable to the impact of dance on body-related perceptions in children and adolescents, even though the studies differ with regard to their intervention content: while we found a high proportion of creative dance techniques in studies for young people, the studies with an adult sample offer step dance, social dance and folk dance with a focus on deductive methods. One possible explanation could be that dance-regardless of style-may strengthen bodyrelated perceptions of participants of different age groups. However, it could also be possible that different age populations benefit from different intervention contents. As the review lacked a study with an adult sample, which compares different dance contents, future research may address this question. Nevertheless, study quality of studies on this outcome field ranges in the middle and upper third for quantitative studies and the qualitative study fulfills eight out ten quality criteria. Therefore, the studies perform better concerning methodological issues in comparison to studies with children/adolescents. In summary, the positive findings on this outcome show that dance may be an alternative intervention content to exercise in studies that aim to promote body-related perceptions in adult populations. Exercise interventions have already been shown to improve physical selfworth and further body-related perceptions in middle aged and older adults (McAuley et al., 1997; Li et al., 2002).

The five studies examining effects on self-efficacy show inconsistent results. One mixed methods study outlines positive development in self-efficacy as the key topic of the discussions and interviews (Stickley et al., 2015). Three out of four quantitative studies reveal no improvement (Pinniger et al., 2013b; Mandelbaum et al., 2016; Kosmat and Vranic, 2017), even though the one study finding positive results reports high effect sizes (Pinniger et al., 2013c). An analysis of the results in view of the intervention characteristics (e.g., population, timeframe, dance content) reveals no explanation for the reasons of these discrepancies: the studies reporting positive results show different characteristics as well as the studies that outline no improvement. An adjacent summary of reviews concerning the effects of yoga interventions on mental and physical health of adults reports positive effects of yoga on self-efficacy (Büssing et al., 2012). Obviously, there exist clear differences between yoga and dance. Nevertheless, yoga as well as dance are characterized through an inner orientation during movement execution and thus may both have a similar impact on aspects of the self. However, the inconsistent results of the studies in this review cannot support this assumption.

For the remaining constructs, the review identified only a small number of studies and therefore evidence is poor. Moreover, the studies that investigate self-esteem or selfconcept/self-image (all quantitative) report inconsistent results (Aşçi, 2009; Baptista et al., 2012; Pinniger et al., 2012, 2013a; Soares Costa de Mendonça et al., 2015), which is similar to the studies with children and adolescents for self-esteem. Nevertheless, two out of three studies that investigate self-esteem find positive effects with high effect sizes (Pinniger et al., 2013a; Soares Costa de Mendonça et al., 2015). Two qualitative studies point out findings in terms of self-development, self-expression and self-confidence. They consistently report a positive impact of dance interventions on the mentioned constructs. These first results could form the basis for future research on these topics.

\section{Dance Intervention Conditions}

The samples of eight out of the thirteen reviewed studies present a wide age range (Baptista et al., 2012; Pinniger et al., 2012, 2013b,c; Fonseca et al., 2014; Soares Costa de Mendonça et al., 2015; Stickley et al., 2015; Mandelbaum et al., 2016). Potential disparities concerning the impact on participants of different age groups cannot be captured, as the studies do not compare subgroups (e.g., younger vs. middle-aged vs. older 
adults). Designing comparative studies that offer the same specific dance program to adults of different age groups would be a possible approach to this question. The samples consist of about 60 participants on average (excluding one study with an exceptional sample size of $N=330$ ). Hence, these studies show little larger sample sizes than those with a population of children/adolescents. However, with respect to the low generalizability of their results, studies with larger sample sizes are desirable for future research. This is also claimed by other authors of a systematic review in the field (Hwang and Braun, 2015).

In contrast to dance interventions for children and adolescents almost half of the studies chose social dance as content (Pinniger et al., 2012, 2013a,b,c; Fonseca et al., 2014; Mandelbaum et al., 2016). According to Pinniger et al., partnered dance requires an awareness of one's own body as well as the partner's body (Pinniger et al., 2012). Moreover, the emphasis of choosing social dance as content may reflect the general meaning of partnered dance for adult generations in comparison to young people. Social dance seems to be especially chosen for adult participants, though the study results (all quantitative studies) are inconsistent and therefore show poor evidence: three studies do not find improvement in self-esteem and self-efficacy (Pinniger et al., 2012, 2013b; Mandelbaum et al., 2016), while three studies report positive effects-with high effect sizes-on the mentioned constructs (Pinniger et al., $2013 \mathrm{a}, \mathrm{c}$ ) or no significant effects but positive tendencies on body size perception (Fonseca et al., 2014). It should be noted that these discrepancies may also be less a result of the specific intervention but of an apparent difficulty in measuring these constructs with quantitative methodologies. Moreover, five out of the six studies investigate a sample with special disorders. The differences concerning the population may be another reason for the inconsistent results. In conclusion, the reviewed studies cannot answer the question whether partnered dance can strengthen aspects of the self for adult populations with or without disorders.

The reviewed studies show different intervention timeframes. With respect to the results, the frequency of the dance sessions for adults seems to play a role especially for short- and mediumduration programs up to 12 weeks. A higher frequency may contribute to more positive effects. For interventions with a duration of at least 16 weeks the frequency seems to play less of a role regarding their effectiveness. In contrast to the reviewed interventions with children/adolescents, frequency is detected as relevant for the effectiveness of dance interventions with adults. However, the study with the longest duration (30 months) does not provide precise information concerning the dance training frequency (Stickley et al., 2015). Due to methodological shortcomings, the study cannot contribute to the assessment of the effects of participating in a long-term dance program on aspects of the self. As dance interventions with a long duration are rare, future research should seek the effects of long-term in comparison to short-term programs.

With regard to study design and quality, we found considerably more randomized controlled trials for adults than for children and adolescents. Eight out of twelve studies with quantitative methodologies are randomized controlled trials (Aşçi, 2002, 2009; Baptista et al., 2012; Pinniger et al., 2012, 2013a,b,c; Kosmat and Vranic, 2017). Moreover, five studies (Baptista et al., 2012; Pinniger et al., 2013b,c; Mandelbaum et al., 2016; Kosmat and Vranic, 2017) conduct follow-up measures, which was rare for studies with a sample of young people. The quality of these studies ranges in the middle and upper third of the rating scale. Only two studies with quantitative measures lack a control group (Stickley et al., 2015; Mandelbaum et al., 2016). The fact that nine out of 12 studies with quantitative measures calculate effect sizes enhances the credibility of the study results, too. However, the studies differ in terms of outcomes, measurement tools and intervention frameworks. Hence, at the current state of research, there is still a too small number of studies of comparable frameworks investigating the same outcome to perform a meta-analysis. Most of the studies have non-active control groups, as already ascertained for studies with young people. This issue is also noted by Hwang and Braun who highlight the effectiveness of dance interventions to improve older adults' physical health (Hwang and Braun, 2015). The consideration of the activity level of the control groups seems to be one respective issue for studies in adults. Nevertheless, with respect to the overall quality and important quality criteria like randomization, control and effect size measures, quantitative studies with adult samples perform better than those with samples of young people.

The review identified only two studies with adults with qualitative measures (Thornberg et al., 2012; Stickley et al., 2015) while one of them fulfills only half of the quality criteria (Stickley et al., 2015). Thus, we are not able to draw a conclusion about the potential benefits of qualitative approaches in this research field from the empirical data. However, as knowledge and evidence on effects of dance interventions are scarce to date, a more open approach with qualitative methodologies may discover impact fields that are rather unknown. As determined for studies with a sample of young people, the two studies with adults show problems in giving a clear declaration of the influence of the researcher on the research, and vice versa (see Table 6, Q7). The importance of the teacher as an influencing factor in a teaching context should be emphasized (e.g., teaching/feedback style). Additionally, both studies lack a statement locating the researchers culturally and theoretically (e.g., information about vocational training/focus) (see Table 6, Q6). We recommend taking such a statement into account, as it can give more insight into the background of the dance intervention, which plays an important role for its development.

\section{General Aspects}

In the following, we discuss issues that seem to be relevant when planning dance intervention studies regardless of their population. These issues may give impulses for future studies in the field.

\section{Investigated Aspects of the Self}

The studies focus on different aspects of the self. The review yielded only a little number of studies focusing on exactly the same outcome, though most of them are closely related. 
For example, quantitative studies investigating body-related perceptions measure the following outcomes: attitudes toward the subject's own body (Blackman et al., 1988), body image (Caf et al., 1997), body self-concept (Studer-Lüthi and Züger, 2012), physical self-perception (Aşçi, 2002), body size perception (Fonseca et al., 2014), satisfaction with physical appearance and body image perception (Soares Costa de Mendonça et al., 2015). This also entails that different measurement instruments are used, which may lead to discrepancies concerning study results. Furthermore, the selection of an appropriate outcome is connected with the range of existing validated questionnaires for quantitative measurements. Roswal et al. address the question of appropriateness of the existing questionnaires in the dance context (Roswal et al., 1988). They highly recommend the development of dance-specific tools for future research. Progress in the field of designing and validating suitable measurement instruments for quantitative research is expected from a research group from Germany ${ }^{6}$. They work on the development of a measurement instrument concerning the dance-specific selfconcept for children at the age of 8 to 12 . More dance specific measurement tools for further population groups are desirable.

Moreover, some quantitative studies choose to measure the effect of dance interventions on the self-concept or rather selfimage of the participants. None of the studies that investigate self-concept report an improvement of the overall construct (Blackman et al., 1988; Roswal et al., 1988; Aşçi, 2009). Only one study finds a positive effect on self-image (Baptista et al., 2012). Looking at these study results, dance interventions do not seem to be able to improve self-concept. However, the review of Burkhardt and Brennan indicates that dance interventions (including fitness dance interventions, e.g., aerobic dance) may improve self-concept, but with the addition that these assumptions are based on very limited evidence (Burkhardt and Brennan, 2012). Stein-referring to Bracken et al.-reports that intervention studies often fail to increase self-concept (Stein, 2011). She emphasizes the insufficient sensitivity of global self-concept to specific treatments. Self-concept or selfimage are constructs of a superordinate level in comparison to subordinated, more specific constructs like the physical self-concept or even more precisely the self-perception of the subject's own dance ability (Marsh and Hattie, 2011). Outcomes at a very general level may be inappropriate for most of the determined timeframes of the reviewed interventions due to their relative stability over time (Marsh and Hattie, 2011). Therefore, future research may ask for the effects of dance in a more specific manner. In relation to the inherent orientation of dance, body awareness-among other things-may be a specific relevant construct. The assessment of potential transfer effects on connected constructs like the physical self-concept may be of interest, too. Connolly et al. also recommend the investigation of constructs that are connected to the uniqueness of dance (Connolly et al., 2011). They point out the inherent creativity in dance, the forum it presents for task-

${ }^{6}$ Giegerich, P. (2017). BMBF-Förderung für die Erforschung von Tanz als Mittel kultureller Bildung. Available online at: https://idw-online.de/de/news670978. and problem-solving as well as the interactions of music and movement.

\section{Presentation of Intervention Contents and Conditions}

The reviewed interventions choose different dance contents. In several cases, we missed detailed information about the intervention content. Some of the reviewed studies do not provide precise information concerning relevant issues in a teaching context, such as teachers' methodical-didactical concepts or lesson contents (see Table 5). Furthermore, the studies choose different dance styles for their intervention. In several studies, the reasons for the choice of a certain dance form is explained (Roswal et al., 1988; Caf et al., 1997; Backe and Graefe, 2004; Zitomer and Reid, 2011; Pinniger et al., 2012, 2013a,b,c; Romero, 2012; Jounghwa et al., 2013; Fonseca et al., 2014; Mandelbaum et al., 2016). However, some studies do not give reasons for their choice of a specific dance style or do not even chose a specific style. Depending on dance form or, even more important, the methodical-didactical way of teaching, there may be more or fewer opportunities to advance participants in aspects of the self, e.g., in terms of self-expression. In such a complex context, diverse factors may influence the study results and should therefore be reported as effectively as possible: information about the teacher, educational approach/focus, methodical-didactical concepts (e.g., normed or non-normed), feedback manner, social setting, participation type or dance style-among others-may be relevant for interpreting reported results. The poor reporting of dance intervention details is also addressed in the review conducted by Burkhardt and Brennan (Burkhardt and Brennan, 2012). They refer to the limited reproducibility of the interventions, when studies do not provide details. Moreover, future research should choose the intervention content in relation to the aim of the intervention. In this case, one has to ask which dance form has the most potential to obtain positive effects on certain psychological constructs. Schmais and White emphasize that dance forms differ concerning their organization and structure, which may place limits on the dance experience (Schmais and White, 1986). This assumption counts for the methodical-didactical concept of teaching dance as well, since different dance styles can be taught in different ways (e.g., implementation of creative teaching methods vs. standardized training of dance techniques). We recommend that future studies open the "black-box" by introducing the intervention content, timeframes and other framework conditions in sufficient detail. Presenting the full details of the intervention components in a separate publication can be an approach to consider the complexity of a dance intervention. Publishing an intervention mapping protocol or the use of checklists for a better reporting of the intervention (e.g., TIDieR guidelines) could be a possibility for future research to present intervention design and contents more precisely (Hoffmann et al., 2014).

\section{Research Approaches and Methods}

We found an emphasis on studies using quantitative measures, especially within adult samples. The review yielded only one study with an adult sample and a purely qualitative approach (Thornberg et al., 2012). Daykin et al. emphasize that qualitative 
methods have already been successfully used in performing arts interventions (e.g., action research, grounded theory, ethnography) (Daykin et al., 2008). Regarding the holistic nature of dance, it seems questionable to choose specific outcomes to be measured (Duberg et al., 2016). However, for a quantitative survey with standardized questionnaires a certain outcome must be focused. Daykin et al. state that a qualitative approach may be more suitable to address impact and process issues in relation to performing arts for health (Daykin et al., 2008). Choosing a research approach and design suitable to the study's objective is seen as a challenge of complex interventions such as performing arts. This statement counts for teaching contexts as well and is highly relevant for future dance intervention studies.

\section{Strengths and Limitations}

The conducted review has certain strengths but also limitations. The review was accomplished according to the PRISMA guidelines to ensure information about the review process and analyses were sufficiently described. Furthermore, we chose relatively open inclusion criteria to identify a wide range of studies in the field. This was due to the fact that the aim was to give an overview of the implemented study approaches, designs and measurements as well as the investigated settings and populations. For the development of future intervention studies in the field, it is important to know if research focused on aspects such as investigating a certain population group in particular or on using quantitative methodologies. However, this open strategy led to a limitation of the comparability of the assessed studies. Additionally, several databases were searched. We arranged the independent screening and study selection process as well as the methodological quality assessment by two reviewers. The CCEERC Quantitative Research Assessment Tool ${ }^{7}$ as well as the JBI Checklist for Qualitative research (Lockwood et al., 2015) were assessed to rate the studies' quality. The search was restricted to journal articles in English or German. We excluded reports and gray literature. Therefore, we cannot rule out the existence of other relevant studies in the field. Due to the screening of titles and abstracts, the review team was dependent on a certain quality of the abstracts to identify relevant studies. Relevant literature could have been lost because of imprecise abstracts. The review relates to educational and teaching contexts and therefore is affected by the critical debate of systematic reviews in an educational context. The reviewers as well as the readers have to be aware of the limitations of a systematic review. In accordance to Andrews, this systematic review must be seen as an attempt to minimize bias (Andrews, 2005). We do not claim to eliminate bias or to present a complete, objective version of the current state of research. However, we chose a systematic approach due to the advantages mentioned in the methods chapter. In using the PRISMA checklists and recommendations we tried to consider the demand for transparency, validity and reproducibility.

\footnotetext{
${ }^{7}$ Quantitative Research Assessment Tool provided by the Child Care and Early Education Research Connections (CCEERC). Available online at: https://www. researchconnections.org/content/childcare/understand/research-quality.html.
}

\section{CONCLUSION}

This systematic review aimed at giving an overview of studies that investigate the effects of dance interventions on aspects of the participants' self. Overall, the review of 24 included studies indicates that a dance intervention can advance the participants in different aspects of the self. Studies with qualitative methodologies find that children/adolescents benefit in body-related perceptions, self-trust, self-esteem, self-expression, and the perception of dance-abilities. Moreover, dance interventions may strengthen self-expression, self-efficacy, self-/body-awareness, self-development, and self-confidence in adults. Studies with quantitative methodologies point out improvement especially for body-related perceptions in children/adolescents as well as in adults. The review revealed heterogeneous results concerning self-esteem and self-efficacy. Furthermore, the evaluated studies show an overall heterogeneous nature of populations, intervention contents, timeframes, outcomes, research methods and study quality. Despite positive findings, evidence for each of the aspects is still poor due to the small number of studies on each construct, inconsistent findings or methodological shortcomings. There is a need for more high-quality studies in the field in order to further evaluate the findings and to gain a deeper understanding of the possible benefits of dance interventions in different populations.

The following recommendations for future intervention studies in the field can be derived from the review: large samples and intervention timeframes are desirable. Especially for quantitative studies with a sample of children and adolescents, the implementation of randomized controlled and quasiexperimental trials with active control groups is detected as an issue for future research. Follow-up measures are needed to examine whether the effects of the dance interventions persist over time. However, it often seems to be difficult to conduct these study designs with complex measurements in school settings. Additionally, future research may consider using mixed methods or qualitative study approaches. The implementation of comparative studies may address the questions of whether different participation types or methodicaldidactical concepts influence study results. As we have to deal with a complexity of the respective construct as well as the interventions themselves, future studies should be designed carefully and with regard to methodological rigor. Researchers should reflect their study approach/design, the intervention content as well as the constructs to be investigated considering the specificity of dance. The design and validation of appropriate measurement instruments in the dance context is desirable. The presentation of the intervention contents, timeframes and other framework conditions in sufficient detail would be beneficial to enable reproducibility of the intervention as well as transparency of the interpretation of the reported results.

\section{AUTHOR CONTRIBUTIONS}

TS, SS, and FM conceived and designed the study. TS and $\mathrm{CO}$ performed the literature search and selection 
process. TS, SS, and CO performed the methodological quality assessment. TS analyzed the data and wrote most of the paper with substantial contributions from SS and FM.

\section{FUNDING}

This work was supported by the German Research Foundation (DFG) and the Technical University of Munich (TUM) in the framework of the Open Access Publishing Program.

\section{REFERENCES}

Akom, A. A. (2009). Critical Hip Hop Pedagogy as form of liberatory praxis. Equity Excel Educ. 42, 52-66. doi: 10.1080/10665680802612519

Allport, G. W. (1954). The Nature of Prejudice. Cambridge: Addison-Wesley Publishing Company.

Amelang, M., Bartussek, D., Hagemann, D., and Stemmler, G. (2011). Differentielle Psychologie und Persönlichkeitsforschung. Stuttgart: Kohlhammer W. GmbH.

Andrews, R. (2005). The place of systematic reviews in education research. Brit. J. Educ. Stud. 53, 399-416. doi: 10.1111/j.1467-8527.2005.00303.x

Aşçi, F. H. (2002). The effects of step dance on physical self-perception of female and male university students. Int. J. Sport Psychol. 33, 431-442.

Aşçi, F. H. (2009). Sex differences in psychological effects of exercise. Int. J. Psychol. 44, 313-320. doi: 10.1080/00207590802325903

Asendorpf, J. B., and Neyer, F. J. (2012). Psychologie der Persönlichkeit. Berlin; Heidelberg: Springer Verlag.

Askevold, F. (1975). Measuring body image: preliminary report on a new method. Psychother. Psychos. 26, 71-77.

Backe, J., and Graefe, C. (2004). “Ich tanz' mein Drinnen!” Zur Verbindung von Tanz und Selbstwertgefuehl - Ergebnisse einer Pilotstudie. / "I'm dancing my inside!": on the connection between dance and self-esteem: results of a pilot study. Praxis der Psychomotorik. 29, 247-254.

Baptista, A. S., Villela, A. L., Jones, A., and Natour, J. (2012). Effectiveness of dance in patients with fibromyalgia: a randomized, single-blind, controlled study. Clin. Exp. Rheumatol. 30(6 Suppl. 74), 18-23.

Baumeister, R. F. (1991). "Self concept and identity, in Personality: Contemporary Theory and Researches, eds V.J. Derlega, B. A. Winstead, and W. H. Jones (Chicago, IL: Nelson), 349-380.

Blackman, L., Hunter, G., Hilyer, J., and Harrison, P. (1988). The effects of dance team participation on female adolescent physical fitness and self-concept. Adolescence 23, 437-448.

Block, B., and Kissell, J. L. (2001). The dance: essence of embodiment. Theor Med. 22, 5-15. doi: 10.1023/A:1009928504969

Bungay, H., and Vella-Burrows, T. (2013). The effects of participating in creative activities on the health and well-being of children and young people: a rapid review of the literature. Perspect. Public Health 133, 44-52. doi: $10.1177 / 1757913912466946$

Burkhardt, J., and Brennan, C. (2012). The effects of recreational dance interventions on the health and well-being of children and young people: a systematic review. Arts Health 4, 148-161. doi: 10.1080/17533015.2012.665810

Büssing, A., ,Andreas, M., Khalsa, S. B. S., Telles, S., and Sherman, K. J. (2012). Effects of yoga on mental and physical health: a short summary of reviews. Evid. Based Complement. Alternat. Med. 30(6 Suppl 74):18-23. doi: 10.1155/2012/165410

Caf, B., Kroflič, B., and Tancig, S. (1997). Activation of hypoactive children with creative movement and dance in primary school. Arts Psychother. 24, 355-365. doi: 10.1016/S0197-4556(97)00016-6

Connolly, M. K., Quin, E., and Redding, E. (2011). Dance 4 your life: exploring the health and well-being implications of a contemporary dance intervention for female adolescents. Res. Dance Educ. 12, 53-66. doi: 10.1080/14647893.2011.561306

\section{ACKNOWLEDGMENTS}

We would like to express our appreciation to Susanne Stortz (Technical University of Munich) for her contribution to the discussion in terms of dance expertise and to Melina Schnitzius (Technical University of Munich) for her writing assistance.

\section{SUPPLEMENTARY MATERIAL}

The Supplementary Material for this article can be found online at: https://www.frontiersin.org/articles/10.3389/fpsyg. 2018.01130/full\#supplementary-material

Coopersmith, S. (1968). The Antecedents of Self-Esteem. San Francisco, CA: Freeman.

Cratty, B. J. (1979). Perceptual and Motor Development in Infants and Children. New York, NY; New Jersey, NJ: Prentice Hall.

Daykin, N., Orme, J., Evans, D., Salmon, D., McEachran, M., and Brain, S. (2008). The impact of participation in performing arts on adolescents health and behaviour. A systematic review of the literature. J. Health Psychol. 13, 251-264. doi: $10.1177 / 1359105307086699$

Deusinger, I. (1998). Die Frankfurter Kãrperkonzeptskalen (FKKS). Handanweisung. Göttingen: Hogrefe.

Dixon-Woods, M., Agarwal, S., Jones, D., Young, B., and Sutton, A. (2005). Synthesising qualitative and quantitative evidence: a review of possible methods. J. Health Serv. Res. Policy 10, 45-53. doi: $10.1177 / 135581960501000110$

Duberg, A., Hagberg, L., Sunvisson, H., and Möller, M. (2013). Influencing self-rated health among adolescent girls with dance intervention a randomized controlled trial. JAMA Pediatr. 167, 27-31. doi: 10.1001/jamapediatrics.2013.421

Duberg, A., Möller, M., and Sunvisson, H. (2016). "I feel free": experiences of a dance intervention for adolescent girls with internalizing problems. Int. J. Qual. Stud. Health Well-being 11:31946. doi: 10.3402/qhw.v11.31946

Dunn, J. M., Morehouse, J. W., and Dalke, B. (1979). Game, Exercise, and Leisure Sport Curriculum. Corvallis: Oregon State University, Department of Physical Education.

Ekeland, E., Heian, F., and Hagen, K. B. (2005). Can exercise improve self esteem in children and young people? A systematic review of randomised controlled trials. Brit. J. Sports Med. 39, 792-798. doi: 10.4073/csr.2005.4

Fitt, S., and Riordan, A. (eds.). (1980). “Anne 's magic," in Focus on dance IX: Dance for the handicapped (Reston, VA: American Alliance for Health, Physical Education, Recreation and Dance), 21-24.

Fonseca, C. C., Thurm, B. E., Vecchi, R. L., and Gama, F. E. (2014). Ballroom dance and body size perception. Percept. Motor Skills 119, 495-503. doi: 10.2466/25.PMS.119c26z1

Fox, K. R., and Corbin, C. B. (1989). The physical self-perception profile: Development and preliminary validation. J. Sport Exerc. Psychol. 11, 408-430.

Fritsch, U. (1988). Tanz, Bewegungskultur, Gesellschaft. Verluste und Chancen Symbolisch-Expressiven Bewegens. Frankfurt a. Main: Afra Verlag.

Gardner, S. M., Komesaroff, P., and Fensham, R. (2008). Dancing beyond exercise: young people's experiences in dance classes. J. Youth Stud. 11, 701-709. doi: 10.1080/13676260802393294

Gurley, V., Neuringer, A., and Massee, J. (1984). Dance and sports compared: effects on psychological well-being. Comparaison danse et sports: les effets sur le bien-etre psychologique. J. Sports Med. Phys. Fitness 24, 58-68.

Guzmán-García, A., Hughes, J. C., James, I. A., and Rochester, L. (2013). Dancing as a psychosocial intervention in care homes: a systematic review of the literature. Int. J. Geriatr. Psychiatry 28, 914-924. doi: 10.1002/gps.3913

Haselbach, B. (1976). Tanz, Improvisation, Bewegung. Stuttgart: Ernst Klett.

Heath, G. W., Pate, R. R., and Pratt, M. (1993). Measuring physical activity among adolescents. Public Health Rep. 108(Suppl 1), 42-46.

Hoffmann, T. C., Glasziou, P. P., Boutron, I. M. R., Perera, R., Moher, D., Altman, D. G., et al. (2014). Better reporting of interventions: template for intervention 
description and replication (TIDieR) checklist and guide. BMJ Brit. Med. J. 348:g1687. doi: 10.1136/bmj.g1687

Hwang, P. W.-N., and Braun, K. L. (2015). The effectiveness of dance interventions to improve older adults' health: a systematic literature review. Alternat. Ther. Health Med. 21, 64-70.

Jago, R., Edwards, M. J., Sebire, S. J., Tomkinson, K., Bird, E. L., Banfield, K., et al. (2015). Effect and cost of an after-school dance programme on the physical activity of 11-12 year old girls: the Bristol Girls Dance Project, a schoolbased cluster randomised controlled trial. Int. J. Behav. Nutr. Phys. Act. 12:128. doi: $10.1186 /$ s12966-015-0289-y

Jeon, J. H. (2005). A Study on Development Model of Secondary School Dance Curriculum as Education. Unpublished dissertation. Seoul: The Ewha Womens University.

Jorge, R. T. B., Neto, M. S, Natour, J., Veiga D. F., Jone, A., and Ferreira, L. M. (2008). Brazilian version of the body dysmorphic disorder examination. Sao Paulo Med. J. 126, 87-95.

Jounghwa, L., Lee, H. J., Bommna, K., and Boswell, B. (2013). Effects of creative dance on students' self-expression and perceptions of dance. Int. J. Appl. Sports Sci. 25, 68-77.

Kaufmann, K. (2011). Movement as a metaphor: how persistence, the tao, and the wisdom of the ostrich helped build school dance programs. J. Phys. Educ. Recreat. Dance 82, 37-45. doi: 10.1080/07303084.2011.105 98627

Keogh, J. W., Kilding, A., Pidgeon, P., Ashley, L., and Gillis, D. (2009). Physical benefits of dancing for healthy older adults: a review. J. Aging Phys. Act. 17, 479-500. doi: 10.1123/japa.17.4.479

Kestenberg, A. J., Lewis, P., Loman, S., and Sossin, M. (1999). The Meaning of Movement - Development and Clinical Perspectives of the Kestenberg Movement Profile. Amsterdam: Gordon and Breach.

Kiepe, M.-S., Stöckigt, B., and Keil, T. (2012). Effects of dance therapy and ballroom dances on physical and mental illnesses: a systematic review. Arts Psychother. 39, 404-411. doi: 10.1016/j.aip.2012.06.001

Kirsch, S. (2005). Im Tanz die Sinne erfahren. Die Ausbildung der Identität durch eine sinnesorientierte Tanzpädagogik. Hamburg: Verlag Dr Kovač.

Koch, S. C. (2011). "Basic body rhythms: from individual to interpersonal movement feedback," in The Implications of Embodiment Cognition and Communication, eds W. Tschacher and C. Bergomi (Exeter: Imprint Academic), 151-171.

Koch, S., Kunz, T., Lykou, S., and Cruz, R. (2014). Effects of dance movement therapy and dance on health-related psychological outcomes: a meta-analysis. Arts Psychother. 41, 46-64. doi: 10.1016/j.aip.2013.10.004

Kosmat, H., and Vranic, A. (2017). The efficacy of a dance intervention as cognitive training for the old-old. J. Aging Phys. Act. 25, 32-40. doi: 10.1123/japa.2015-0264

Laban, R. (1948). Modern Educational Dance. London: Macdonald \& Evans.

Laban, R. V. (1981). Der moderne Ausdruckstanz in der Erziehung: Eine Einführung in die kreative tänzerische Bewegung als Mittel zur Entfaltung der Persönlichkeit. Wilhelmshaven: Heinrichshofen.

Laban, R. V. (1988). Der moderne Ausdruckstanz in der Erziehung: Eine Einführung in die kreative tänzerische Bewegung als Mittel zur Entfaltung der Persönlichkeit. 3. Auflage. Wilhelmshaven: Florian Noetzel.

Li, F., Harmer, P., Chaumeton, N. R., Duncan, T. E., and Duncan, S. C. (2002). Tai chi as a means to enhance self-esteem: a randomized controlled trial. J. Appl. Gerontol. 21, 70-89. doi: 10.1177/073346480202100105

Lockwood, C., Munn, Z., and Porritt, K. (2015). Qualitative research synthesis: methodological guidance for systematic reviewers utilizing meta-aggregation. Int. J. Evid. Based Healthc 13, 179-187. doi: 10.1097/XEB.0000000000000062

Mandelbaum, R., Triche, E. W., Fasoli, S. E., and Lo, A. C. (2016). A Pilot Study: examining the effects and tolerability of structured dance intervention for individuals with multiple sclerosis. Disabil. Rehabil. 38, 218-222. doi: 10.3109/09638288.2015.1035457

Marsh, H. W. (ed.). (1992). "Self Description Questionnaire (SDQ) II: A theoretical and empirical basis for the measurement of multiple dimensions of adolescent self-concept," in Tets Manual and Research Monograph (Sydney, NSW: University of Western Sydney, Faculty of Education).

Marsh, H. W., and Shavelson, R. J. (1985). Self-concept: its multifaces, hierarchical structure. Educ. Psychol. 20, 107-123. doi: 10.1207/s15326985ep 2003_1
Marsh, H., and Hattie, J. (2011). "Theoretical perspectives on the structure of self-concept," in Handbook of Self-concept: Developmental, Social, and Clinical Considerations, (New York, NY: John Wiley and Sons), 38-90.

Martinek, T. J., and Zaichkowsky, L. D. (1977). Self-Concept Scale for Children. Monterey, CA: Publishers Test Service.

McAuley, E., Mihalko, S. L., and Bane, S. M. (1997). Exercise and selfesteem in middle-aged adults: multidimensional relationships and physical fitness and self-efficacy influences. J. Behav. Med. 20, 67-83. doi: 10.1023/A:1025591214100

McHugh, M. L. (2012). Interrater reliability: the kappa statistic. Biochem. Med. 22, 276-282. doi: 10.11613/BM.2012.031

Moher, D., Shamseer, L., Clarke, M., Ghersi, D., Liberati, A., Petticrew, M., et al. (2015). Preferred reporting items for systematic review and meta-analysis protocols (Prisma-P) 2015 statement. Syst. Rev. 4:1. doi: 10.1186/2046-4053-4-1

Neuber, N. (2000). Kreative Bewegungserziehung - Bewegungstheater. Aachen: Meyer \& Meyer.

Peichl, J. (2013). Das Verhältnis des Selbst zu seinen Teilen: basisdemokratische Vielfalt oder hierarchische Struktur - ein Vergleich der Theoriekonzepte. Psychotherapie 18, 199-213.

Peter-Bolaender, M. (1991). Förderung von körperbewusstheit und körperbewusstsein durch tanzimprovisation," in Körpererfahrung Grundlagen Menschlichen Bewegungsverhaltens 2, ed J. Bielefeld (Göttingen: Hogrefe Verlag Gmbh \& Co), 252-277.

Pinniger, R., Brown, R. F., Thorsteinsson, E. B., and McKinley, P. (2013a). Tango programme for individuals with age-related macular degeneration. Brit. J. Vis. Impairment 31, 47-59. doi: 10.1177/0264619612470651

Pinniger, R., Brown, R. F., Thorsteinsson, E. B., and McKinley, P. (2012). Argentine tango dance compared to mindfulness meditation and a waiting-list control: a randomised trial for treating depression. Complement. Ther. Med. 20, 377-384. doi: $10.1016 /$ j.ctim.2012.07.003

Pinniger, R., Thorsteinsson, E. B., Brown, R. F., and McKinley, P. (2013b). Tango dance can reduce distress and insomnia in people with self-referred affective symptoms. Am. J. Dance Ther. 35, 60-77. doi: 10.1007/s10465-012-9141-y

Pinniger, R., Thorsteinsson, E. B., Brown, R. F., and McKinley, P. (2013c). Intensive tango dance program for people with self-referred affective symptoms. Music Med. 5, 15-22. doi: 10.1177/1943862112470143

Rigby, S. A., Domenech, C., Thornton, E. W., Tedman, S., and Young C. A. (2003). Development and validation of a self-efficacy measure for people with multiple sclerosis: the Multiple Sclerosis Self-efficacy Scale. Mult Scler. 9, 73-81.

Rodrigues-Krause, J., Farinha, J. B., Krause, M., and Reischak-Oliveira, Á. (2016). Effects of dance interventions on cardiovascular risk with ageing: systematic review and meta-analysis. Complement. Ther. Med. 29, 16-28. doi: $10.1016 /$ j.ctim.2016.09.004

Roid, G. H., and Fitts, W. H. (1991). Tennessee Self-Concept Scale: Revised Manual. Los Angeles, CA: Western Psychological Services.

Romero, A. J. (2012). A pilot test of the latin active hip hop intervention to increase physical activity among low-income mexican-american adolescents. Am. J. Health Prom. 26, 208-211. doi: 10.4278/ajhp.090123-ARB-24

Rosenberg, M. (1965). Society and the Adolescent Self-Image. Princeton, NJ: Princeton University Press.

Roswal, P. M., Sherrill, C., and Roswal, G. M. (1988). A Comparison of data based and creative dance pedagogies in teaching mentally retarded youth. Adapt. Phys. Act. Q. 5, 212-222. doi: 10.1123/apaq.5.3.212

Ryan, R. M., and Deci, E. L. (2000). Self-determination theory and the facilitation of intrinsic motivation, social development, and well-being. Am. Psychol. 55, 68-78. doi: 10.1037/0003-066X.55.1.68

Schauder, T. (1991). Die Aussagen-Liste zum Selbstwertgefühl von Kindern und Jugendlichen Manual. Weinheim: Beltz Test GmbH.

Schmais, C., and White, E. Q. (1986). Introduction to dance therapy. Am. J. Dance Ther. 9, 23-30. doi: 10.1007/BF02274236

Schütz, A. (2003). Psychologie des Selbstwertgefühls: Von Selbstakzeptanz bis Arroganz. Stuttgart: Kohlhammer.

Schwarzer, R., and Jerusalem, M. (1995). "Generalized self-efficacy scale," in Measures in Health Psychology: A User's Portfolio. Causal and Control Beliefs, eds J. Weinman, S. Wright, and M. Johnston (Windsor, UK: NFER-Nelson), 35-37.

Secord, P. F., and Jourard, S. M. (1953). The appraisal of body-cathexis: bodycathexis and the self. J. Consult. Psychol. 17, 343-347. doi: 10.1037/h0060689 
Soares Costa de Mendonça, R. M., Targino de Araújo Júnior, A., do Socorro Cirilo de Sousa, M., and Miguel Fernandes, H. (2015). The psychological health of women after 16 weeks of practicing different exercise programs. J. Exerc. Physiol. 8, 32-44.

Stein, R. J. (2011). "Physical self-concept," in Handbook of Self-Concept Development, Social, and Clinical Considerations, ed B. A. Bracken (New York, NY: John Wiley and Sons), 374-394.

Stickley, T., Paul, K., Crosbie, B., Watson, M., and Souter, G. (2015). Dancing for life: an evaluation of a UK rural dance programme. Int. J. Health Prom. Educ. 53, 68-75. doi: 10.1080/14635240.2014.942438

Storch, M., Cantieni, B., Hüther, G., and Tschacher, W. (2011). Embodiment. Die Wechselwirkung von Körper und Psyche verstehen und nutzen. Bern: Huber.

Strassel, J. K., Cherkin, D. C., Steuten, L., Sherman, K. J., and Vrijhoef, H. J. (2011). A systematic review of the evidence for the effectiveness of dance therapy. Altern. Ther. Health Med. 17, 50-59.

Studer-Lüthi, B., and Züger, B. (2012). Auswirkung einer Tanzintervention auf Körperkonzept und kognitive Fähigkeiten von regulär entwickelten Kindern. Musik Tanz Kunstther. 23, 70-77. doi: 10.1026/0933-6885/ a000077

Stunkard, A. J., Sorenson, T., and Schlusinger, F. (1983). "Use of the Danish Adoption Register for the study of obesity and thinness," in The Genetics of Neurological and Psychiatric Disorders, eds S. S. Kety, L. P. Rowland, R. L. Sidman, and S. W. Matthysse (New York, NY: Raven), $115-120$.
Thornberg, K., Lindquist, I., and Josephsson, S. (2012). Experiences of healthy elderly participating in a creative dance workshop. Adv. Physiother. 14, 71-77. doi: 10.3109/14038196.2012.662696

Tschacher, W., and Bergomi, C. (2011). The Implications of Embodiment. Cognition and Communication. Introduction. Exeter: Imprint Academic.

Ullmann, L. (2001). "Einige Hinweise für das Studium von Tanz und Bewegung, " in Der moderne Ausdruckstanz in der Erziehung Eine Einführung in die kreative tänzerische Bewegung als Mittel zur Entfaltung der Persönlichkeit, 5, ed R. Laban (Auflage: Florian Noetzel), 123-148.

Zitomer, M. R., and Reid, G. (2011). To be or not to be-Able to dance: Integrated dance and children's perceptions of dance ability and disability. Res. Dance Educ. 12, 137-156. doi: 10.1080/14647893.2011.575224

Conflict of Interest Statement: The authors declare that the research was conducted in the absence of any commercial or financial relationships that could be construed as a potential conflict of interest.

Copyright (-) 2018 Schwender, Spengler, Oedl and Mess. This is an open-access article distributed under the terms of the Creative Commons Attribution License (CC BY).

The use, distribution or reproduction in other forums is permitted, provided the original author(s) and the copyright owner(s) are credited and that the original publication in this journal is cited, in accordance with accepted academic practice. No use, distribution or reproduction is permitted which does not comply with these terms. 